Elsevier required licence: (c) <2019>. This manuscript version is made available under the CC-BY-NC-ND 4.0 license http://creativecommons.org/licenses/by-nc-nd/4.0/

The definitive publisher version is available online at https://doi.org/10.1016/j.rser.2019.01.010 


\title{
A Review on Economic and Technical Operation of Active Distribution Systems
}

\author{
M. Jabbari Ghadi ${ }^{1}$, Sahand Ghavidel ${ }^{2}$, Amin Rajabi ${ }^{3}$, Ali Azizivahed ${ }^{4}, \mathrm{Li} \mathrm{Li}^{5}$, Jiangfeng Zhang ${ }^{6}$
}

School of Electrical and Data Engineering,, University of Technology Sydney, NSW 2007, Australia

\begin{abstract}
Along with the advent of restructuring in power systems, considerable integration of renewable energy resources has motivated the transition of traditional distribution networks (DNs) toward new active ones. In the mean while, rapid technology advances have provided great potentials for future bulk utilization of generation units as well as the energy storage (ES) systems in the distribution section. This paper aims to present a comprehensive review of recent advancements in the operation of active distribution systems (ADSs) from the viewpoint of operational time-hierarchy. To be more specific, this time-hierarchy consists of two stages, and at the first stage of this time-hierarchy, four major economic factors, by which the operation of traditional passive DNs is evolved to new active DNs, are described. Then the second stage of the time-hierarchy refers to technical management and power quality correction of ADSs in terms of static, dynamic and transient periods. In the end, some required modeling and control developments for the optimal operation of ADSs are discussed. As opposed to previous review papers, potential applications of devices in the ADS are investigated considering their operational time-intervals. Since some of the compensating devices, storage units and generating sources may have different applications regarding the time scale of their utilization, this paper considers real scenario system operations in which components of the network are firstly scheduled for the specified period ahead; then their deviations of operating status from reference points are modified during three time-intervals covering static, dynamic and transient periods.
\end{abstract}

\section{Index Terms}

Active distribution systems (ADSs), Distributed energy resources, Energy storage (ES) systems, Network management.

${ }^{1}$ Corresponding Author: M. Jabbari Ghadi; Postal address: Faculty of Engineering and Information Technology, University of Technology, Sydney, PO Box 123, Broadway, NSW 2007, Australia; Phone: +61-466996685, E-mail: Mojtaba.JabbariGhadi@uts.edu.au 


\section{Nomenclature}

\begin{tabular}{|c|c|}
\hline ADS & Active distribution system \\
\hline CAES & Compressed air energy storage \\
\hline DER & Distributed energy resource \\
\hline DG & Distributed generation \\
\hline DGO & Distributed generation owner \\
\hline DISCO & Distribution Company \\
\hline $\mathrm{DN}$ & Distribution network \\
\hline DR & Demand response \\
\hline DSO & Distribution system operator \\
\hline EMS & Energy management system \\
\hline EPS & Electric power system \\
\hline ES & Energy storage \\
\hline ISO & Independent system operator \\
\hline LV & Low voltage \\
\hline MG & Microgrid \\
\hline MAIFI & Momentary average interruption frequency index \\
\hline OLTC & On-load tap changer \\
\hline PV & Photovoltaic \\
\hline PEV & Plug-in electric vehicle \\
\hline RES & Renewable energy source \\
\hline SOP & Soft open point \\
\hline SVC & Static VAR compensator \\
\hline STATCOM & Static synchronous compensator \\
\hline SAIDI & System average interruption duration index \\
\hline SAIFI & System average interruption frequency index \\
\hline TSO & Transmission system operator \\
\hline WT & Wind turbine \\
\hline
\end{tabular}


During recent years, the planning, operation, and management of electrical distribution networks have been revolutionized due to the great changes that have occurred in different areas of power systems. Moreover, future distribution networks (DNs) will be progressively equipped with smart communication infrastructures and system monitoring and control facilities and will employ more small-scale distributed generation (DGs). They will also benefit from the advantages of new methods of data analysis techniques. Formation of active distribution systems (ADSs) is regarded in [1] as an operational methodology to solve the complications related to high-penetration of intermittent renewable energy sources (RESs), interactions between network and storage facilities as well as the operation analysis of smart grids. The research investigates the potential definitions of ADSs and their specific characteristics. Besides, some key technologies for establishing ADSs are presented, including a unified ADS planning, the necessity for a coordinated control based on both global optimization and distributed autonomy, a flexible method for power flow managing, and also some approaches for economic objectives evaluation. Similarly, [2] looks at changes from

13 traditional networks towards ADSs. The paper focuses on the required changes in the design of networks, coping with 14 variable frequencies and voltages, the need for innovations in wide ranges of information technology, and challenges related to active control of DNs. Protection and grid recovery after fault events are among other issues which have been studied in this paper. Authors have also mentioned to the necessity for real-time simulations to analyze the performance of networks as tools to support system operators for making critical decisions. The paper highlights the inevitability for the existence of advanced sensors and measurement tools to reach higher degrees of grid automation for having an intelligent reconfigurable system.

In addition to planning techniques, optimal operation of DNs plays a vital role for the appropriate integration of RESs, power provision to consumers as well as economic energy management. Power losses reduction, reliability and power quality improvement, competence for greater penetration of DGs, and energy consumers' satisfaction are among other advantages of optimal operating ADS. These facts confirm the value of the effective utilization of these facilities to support and improve ADSs operation [3]. In such the environment, besides the efficient planning of the ADSs, the optimal operation of these new smart DNs has turned into a major concern for power system managers from different technical and economic perspectives.

In this regard, [4] introduces ADS management as a key means for the smooth incorporation of distributed energy resources (DERs) into power systems. Authors have considered distribution system operators (DSOs) as the leading integrators of DERs into the European electricity market on their ways to maximize share of RESs in overall energy consumption; and a major part of these resources, comprising intermittent wind and solar, will be connected to medium 
and low voltage DNs instead of having largescale wind or solar farms. The paper investigates the current situation of several European countries which are already enjoying a high DER penetration like Spain, Germany, and Ireland. It is also has mentioned some regions in these countries in which the installed capacity of RESs connected to the DNs already exceeds the peak load-demand of the area. Finally, this paper summarizes the EURELECTRIC findings and recommendations of ADSs management. Another research in the case of ADSs operation has been presented in [5]; where authors refer to potentials of DERs as dispatchable units to efficiently be scheduled in order to reach definite operating objectives, for example, voltage regulation and costs minimization. Accordingly, the paper highlights the necessity for DSOs to alter DNs from the traditional passive operation to an active operation approach. It also has been mentioned that a challenging task is to formulate the operating characteristics of various types of DERs and incorporate them into the scheduling approaches of ADSs. This issue has been extensively investigated in the study. After

11 discussing the challenges of traditional DNs to accommodate the high penetration of DERs, [6] proposes ADSs as one 12 of the alternative solutions based on advanced metering infrastructure and the application of 13 information/communication technology. In this paper, the effects of DERs on the traditional DNs are examined, and 14 thus the inevitability of developing ADSs is clarified; the fundamental concept of ADSs, the tendency for research, the different aspects of traditional DNs and ADSs, and corresponding study outcomes have been introduced. Finally, some cost-effective enabling technologies which are for the transitions from the existing DNs to the active distribution network were discussed.

A common perspective in the review papers, especially for the sake of ADSs planning, is to explore recent researches based on effects of network components (i.e., generating, energy storage (ES) and, regulation units) on different objectives. Though given the time interval of their applications, the potential applications of these components will change significantly and it has been neglected in most of the researches. In this regard, [7] provides an overview on the formulation of ADSs operation, objectives, control architecture, and analysis of ADS components in the first part of the paper. Numerical and heuristic methods of solving the optimization problem of ADS operating as well as challenges and future research are detailed in the next sections.

Obviously, the days-ahead scheduling and optimal operation of such developed infrastructures in a restructured power market need more investigations of researchers and system operators. The operation of ADSs can be divided into (1) scheduled operating of the grid, mostly one-day ahead (or more days) scheduling which is planned based on the forecasts of RESs generations and load demand. These scheduling programs are mostly based on economic factors and also adding some other objectives like emission minimization, power loss improvement or voltage regulation; (2) real-time operating of the network, modification commands to change DN working point and their corresponding 
actions occur in short time periods employing communication signals and state-estimation algorithms. This paper aims to provide a taxonomy for the operation of ADSs in two different time-scales for days-ahead and technical management. In this respect, the main contributions of the paper can be concluded as: First, comparing to a large number of review papers in case of DNs planning, a limited number of papers have been presented on ADS operation addressing some specific issues. To this end, this paper aims to present a comprehensive review on recent advancements regarding ADSs operation with a broader perspective. Secondly, applying a new time-hierarchy viewpoint, recent researches are categorized into two sections of economic and technical management of DNs based on operation time-intervals. The first time-interval refers to the days-ahead (i.e., 1-3 days) management of the grid which necessitates economic scheduling of the system. Four major tendencies and their respective implementation approaches for the economic ADSs operation are detailed in this section. The second time-interval refers to the daily

11 operation of the DN in terms of technical management and power quality correction which includes three sub-

12 conditions of static, dynamic and transient. In fact, set-points provided in the first interval are reference points for the second interval. Finally, the last part of the paper investigates studies related to modeling and control requirements for

14 implementation of approaches detailed in two previously mentioned intervals. In other words, this paper highlights 15 potentials applications of DOS' properties respecting the time-interval of their application during operating procedures.

To this end, a number of these researches are categorized into the following sections as follows:

\section{ECONOMIC MANAGEMENT OF ADSS}

18 Economic aspects of the DNs operation in the new structure of electric power system (EPS) management can be 19 considered as the most important objective for DSOs and (Distribution Company) DISCOs. However several different 20 objectives of scheduling can be observed in various researches, and there are a considerable number of papers in which 21 those objectives have been transformed to economic indices.

\section{A. DAY-AHEAD SCHEDULING OF DERS AND ES SYSTEMS}

Along with the formation of deregulated power market and participation of DISCOs in the energy market, economic retail company trades with both spot and real-time markets. In this respect, a scheduling method for active/reactive powers of the upstream bus, DERs, ESs and controllable loads is presented in [8] in order to minimize operating cost 


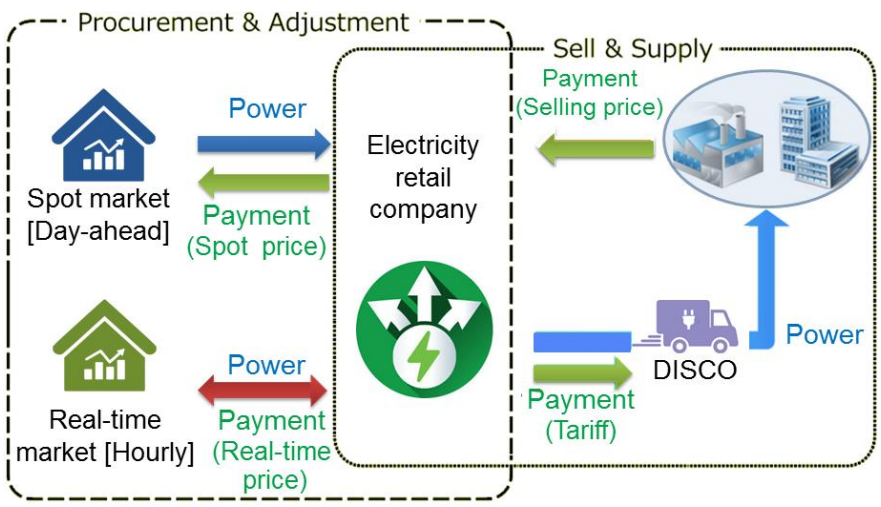

Fig. 1. Participation of DISCOs in energy market

3 carried out in [9] using power flow control and rapid reconfiguration of the DN. Back-to-back voltage source

4 converters are employed to guarantee the power flow control. Moreover, the setting of on-load tap changer (OLTC),

5 power imported from the upstream grid and level of DG curtailment are regarded as controlling tools for ADSs. In addition to daily scheduling, two marginal scenarios including $a$ ) no generation/high demand and $b$ ) high generation/low demand are investigated. In [9], minimization of power curtailment for renewable-based DERs is added to the objectives of [8] by using a multi-objective methodology. Interruptible loads and ESs are also incorporated in this study to provide a set of compromised solutions among different objectives. The proposed concept is applied on a DN with two sub-regions and an inter-regional tie line to reach the maximum exploitation of renewable energy.

11 A robust optimization problem for active/reactive powers is proposed in [10] to minimize the power losses, cost for 12 electricity imported from the main-grid, wind power curtailment, and operational costs caused by OLTC, capacitor bank, static VAR compensator (SVCs), and ESs. Based on a weighting technique, network voltage deviation and

14 operating expenditures are combined and used as an objective in [11] to obtain an operating time-table for 15 active/reactive powers of wind turbine (WT), photovoltaic (PV) and ES units.

Formation of intraday market for DNs besides the day-ahead wholesale market has provided a new environment for the market participants to schedule their facilities more efficiently within these markets. This structure is detailed in Fig. 2. Based on this structure, a two-stage scheduling method is proposed in [12] for the management of dispatchable generators, PV field, wind plants, and OLTC equipped transformers. In the first stage, a day-ahead scheduler is proposed to reach minimum generation cost while meeting a set of electrical and thermal loads based on forecasted data. At the second step, an intra-day scheduler is implemented for every 15 -min intervals to prevent the violations in distribution system constraints. Similarly, a dual-scheduling technique is presented in [13] where a day-ahead energy import/export is determined at the first step; while corrective set-point scheduling of DGs, ESs, OLTC equipped transformers and SVCs to compensate active/reactive and Volt/VAR deviations from day-ahead commitment are obtained in the second step. 


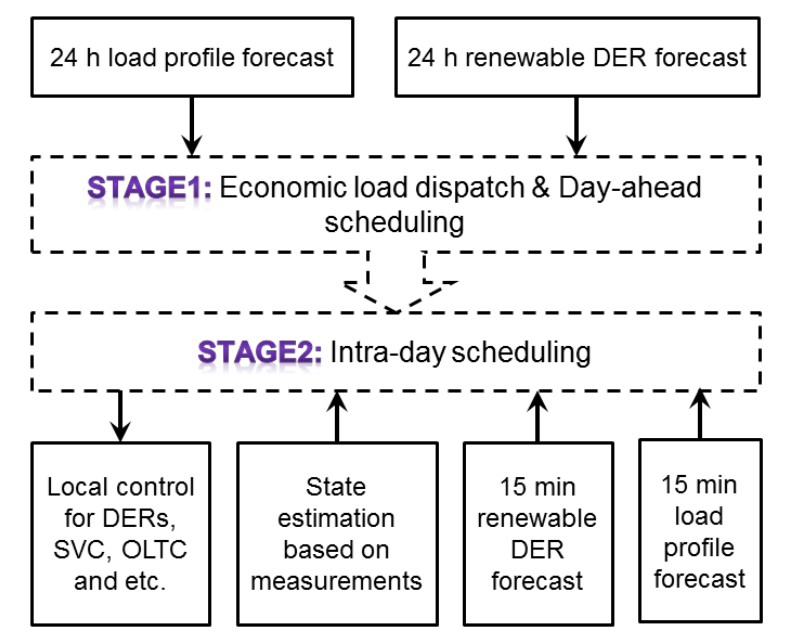

Fig. 2. Two-stage participation of DN operators in day-ahead and intraday energy markets

\section{B. Participation OF DiSCOS In Wholesale MARKeT}

4 In traditional DNs, DSOs are responsible of employing operation methods to simultaneously ameliorate the 5 operating indices of the grid as well as minimizing the total cost. However during recent years, DISCOs have got the responsibility of a section of grid and played more important roles in energy markets. Consequently, based on their own objectives, operation methods of the part of grid owned by DISCO have also been changed. This sub-section aims to investigate recent contributions in this regard. It is worthy of mentioning that based on structure of electricity market in different countries, there is option for DISCOs to trade with separate energy retail companies or directly participate in real-time markets, to provide necessary energy for secure operation of their own grid. In this regard, a

11 bi-level programming model for the optimal participation of retailers and customers in an ADS is investigated in [14].

In the first level of the proposed methodology in [14], the retailer tries to maximize its profit by determining a set

13 of flexible selling price over a day; while the customers define their load levels corresponding to offering prices of

14 retailer in order to minimize the cost of purchasing power. Considering different load patterns of the customers,

15 objective function for each of customers is defined separately. The utilization and operation scheduling of transportable

ES systems with the aim of maximizing the profit of DISCO by participating in the day-ahead market is formulated in

17 [15] which minimizes the total cost comprised of the power imported from the upstream grid, renewable DERs purchasing cost, and DG running cost. This approach is applicable to simultaneous control of active/reactive powers. during recent years in order to cope with the fluctuations of the energy market prices as well as uncertainties of DNs.

21 In [16], the DISCO is responsible for PEVs' charging/discharging scheduling to minimize the total operational costs 
approaches. In [17], a local power company aims to maximize its economic benefits by proposing a flexible operation technique for PEVs in the form of an optimal management methodology of ADS. The presented methodology is jointly applied with an active mechanism of curtailment for the DERs besides the PEVs management. Moreover, two smart strategies of PEVs control are proposed in addition to evaluating the effect of the initial state-of-charge of PEVs.

\section{C. OPTIMAL CONTROL OF PEV LOADS}

Without any doubt, economic charging of PEV devices is one of the most noteworthy challenges for modern microgrids (MGs) and DNs [18]. From one side, network managers tend to reach higher penetration of PEV charging structures; while from the other side, charging load of these units can significantly influence economic and technical parameters of network. Considering the fact that it is difficult to build or upgrade network, novel charging control and energy management strategies should be adopted in order to reach proper integration of these units. As a result, several studies have been accomplished to control the PEVs charging load in ADSs. In [19], a detailed technique of coordinating PEV aggregators with a three-phase DN has been studied. The presented hierarchical framework (i.e.

13 including PEV level and DN level) can benefit both of PEV and DSOs by minimizing the active power loss and the cost related to the PEV charging. In [20], the fuzzy logic is applied to provide an autonomous control for charging load of PEVs with economic objectives as well as targets to maintain system voltage profiles. In [21], from the viewpoint of day-ahead scheduling, a day-ahead tariff of the DN is proposed to avoid grid congestions due to PEVs charging. The locational marginal price and minimal marginal congestion costs are considered as the basis of the day-ahead tariff. Utilizing the predictions of hourly energy prices as well as the day-ahead tariff, the PEV fleet operator sets a schedule for vehicles to avoid congestions while decreasing the cost of the PEVs charging.

As a part of parallelization of different sections of electricity market and network operations, new concepts of decentralized control and management of systems are recently emerged. Agents and agent-based control of the system are among these novel concepts which have been proposed in several types of research for both of planning and operation phases. Definition and tasks related to the modeling of them in ADSs are detailed in Table I. Authors in [22] propose an agent-based approach for controlling the charging of EVs. Three different levels of EV management systems including EV agents, local area agent and coordinator agent are considered in this paper. Besides normal operation of ADS, emergency and demand reduction conditions are also studied in this paper. Reference [23] focuses on prediction of day-ahead hourly charging demand of EVs from the viewpoint of DSO. The copula method is employed for forming a nonlinear reliance among multivariate characteristics of a considerable amount of EVs. 

schedule of the PEVs. The results will benefit aggregators to reduce both their electricity payments and peak demands.

Table I POSSIBLE AGENT BASED OUTLINE FOR MODELING OF ADS

\begin{tabular}{|c|c|}
\hline Agent & Responsibility \\
\hline Grid & $\begin{array}{l}\text { 1. Energy trading } \\
\text { 2. State estimation } \\
\text { 3. Power routing } \\
\text { 4. Voltage regulation } \\
\text { 5. DG control signal } \\
\text { 6. Ancillary service } \\
\text { 7. Power matching }\end{array}$ \\
\hline DG & $\begin{array}{l}\text { 1. Executing control commands } \\
\text { 2. Sharing storage limits } \\
\text { 3. Sharing generating forecasts }\end{array}$ \\
\hline Feeder & $\begin{array}{l}\text { 1. Summing up loads connected to feeder } \\
\text { 2. Sharing next hour capacity } \\
\text { 3. Checking operating constraints violation }\end{array}$ \\
\hline Storage & $\begin{array}{l}\text { 1. Sharing storage capacity } \\
\text { 2. Responding to charge/discharge controlling commands }\end{array}$ \\
\hline Consumer & $\begin{array}{l}\text { 1. Load forecasting } \\
\text { 2. Sharing estimated required power for substation } \\
\text { 3. Sharing DR potential } \\
\text { 4. Sharing PEV potential } \\
\text { 5. Forecasting power of DGs connected to low voltage (LV) grid } \\
\text { 6. Making Price negotiation }\end{array}$ \\
\hline $\begin{array}{l}\text { Primary } \\
\text { substation }\end{array}$ & $\begin{array}{l}\text { 1. Initiating route token } \\
\text { 2. Initiating alarm token } \\
\text { 3. Coordinating state estimation } \\
\text { 4. Embedding control actions from GRID AGENT in token }\end{array}$ \\
\hline $\begin{array}{l}\text { Secondary } \\
\text { substation }\end{array}$ & $\begin{array}{l}\text { 1. Summing up loads connected to it } \\
\text { 2. Sharing next hour capacity } \\
\text { 3. Checking operating constraints violation } \\
\text { 4. Local state estimation }\end{array}$ \\
\hline
\end{tabular}

\section{D. MG FORMATION FOR DECENTRALIZED MANAGEMENT OF ADS}

5 Utilization of the concept of MGs is also an effective tool for the economic management of ADS [24]. High

6 penetration of DGs in low-voltage (secondary) DNs as one of the fundamental challenges of DSOs has been

7 investigated in [25]. The paper focuses on daily operation analysis of radial LV DNs including MGs; while studying

8 impacts of bidirectional power flow and renewable generation intermittency which cause serious concerns in terms of

9 high energy losses, line overloads, and over/under voltages. Ref. [26] covers the vital necessity to develop an organized

10 method for optimal construction of MGs. In fact, the paper develops some optimized and efficient approaches to cluster

11 DNs into a set of virtual MGs which have capability of self-adequacy. Then, the potential benefits of installing both

12 distributed reactive sources and ESs are investigated to increase the self-adequacy of the designed MGs. A similar

13 study in case of MG formation for daily operation of ADSs considering reliability indices and self-adequacy has been

14 accomplished in [27]. With the aim of formation of MGs, as it can be seen in Fig. 3, the DN will be clustered to several 


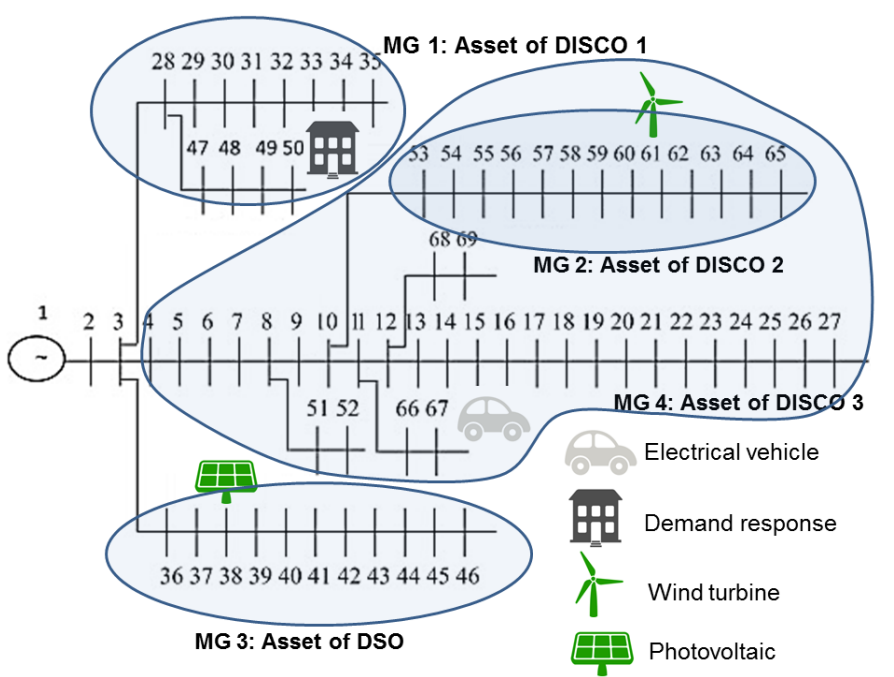

Fig. 3. Clustering of network to several MGs as DSO or DISCO assets

In such a situation, each of DISCOs besides DSO can independently participate in energy markets; however, the DSO is still in charge of maintaining security of the grid. Based on this framework, authors in [28] present a technique of employing several MGs connected to others in an ADS with the aim of maximizing the benefit of each independent system. This paper proposes a methodology based on the model of "system of systems" in which the DISCO and MGs are considered as individual agents with their own assets while having information exchange with each other based on a hierarchical optimization procedure. In a similar framework, [29] presents a dynamic energy management systems (EMS) for ADSs based on MGs management considering both the influence of large-scale DERs integration and the interaction of energy in a DN. Moreover, an extended ES system is proposed in this research using the remaining capacity of controllable DGs and ES units. In order to optimize the interactions among the group of MGs and DSO, and, subsequently to maximize the profit of each individual, an interactive energy game matrix is defined. In [30], a simultaneous operation of generation and distribution systems with the cooperation of independent system operator (ISO) and DSOs has been proposed in which the optimal security constrained scheduling of several thermal generating units from ISO's prospective besides the units existing in two MGs from DISCO's prospective are accomplished. A decentralized plan based on the concept of "system of systems" is established to minimize the operational cost of individuals while satisfying the constraints related to secure operation of ISO and DISCOs.

\section{TECHNICAL MANAGEMENT AND POWER QUALITY IMPROVEMENT}

The technical management of ADS with the aim of reaching optimal operation indices and power quality 
related to this objective have been among the major concerns of power system managers during recent years, specifically for DSOs and DISCOs in distribution sections which utilize high amount of different types of DGs and power electronic devices. Volt/VAR optimization, power loss improvement, harmonic suppression, and enhancement of reliability indices are noted as the main concerns in ADSs. Research in these respects can be generally categorized into static and dynamic (hourly scheduling) types; however, some researchers have also paid attention to transient periods (several seconds to less than one hour) [31]. From another point of view, as it can be seen from Table II, these methods can also be categorized into the centralized and decentralized methods.

Table II COMPARISON OF DIFFERENT TYPES OF SYSTEM CONTROL IN ADS

\begin{tabular}{|c|c|c|}
\hline $\begin{array}{c}\text { Volt/VAR } \\
\text { management method }\end{array}$ & Advantages & Limitations \\
\hline Local control & $\begin{array}{l}\text { 1. Scalable } \\
\text { 2. Low cost } \\
\text { 3. Low needs for communication }\end{array}$ & $\begin{array}{l}\text { 1. Negative interaction of some devices } \\
\text { 2. Necessitates complex safety restrictions } \\
\text { 3. Problem in DGs integration }\end{array}$ \\
\hline Centralized control & $\begin{array}{l}\text { 1. More efficient during most conditions } \\
\text { 2. Less protection limitations to access the } \\
\text { remote measurements }\end{array}$ & $\begin{array}{l}\text { 1. Necessitates more communication } \\
\text { 2. No adaption to changes in feeder configuration } \\
\text { 3. No adaption to changes in operation state } \\
\text { 4. No coordination between different kinds of } \\
\text { regulation devices } \\
\text { 5. Problems for DGs integration }\end{array}$ \\
\hline Model-based control & $\begin{array}{l}\text { 1. High coordination, optimal solution } \\
\text { 2. Robust to change in system configuration } \\
\text { and operation using real-time update of } \\
\text { system state } \\
\text { 3. Acceptable integration of DGs }\end{array}$ & $\begin{array}{l}\text { 1. Not highly scalable - control system for whole DN } \\
\text { 2. High costs of implementation and then operation } \\
\text { due to technical challenges of system robustness and } \\
\text { efficiency }\end{array}$ \\
\hline
\end{tabular}

\section{A. STATIC REACTIVE POWER OPTIMIZATION OF GRID}

9 As one of the ancillary services in power market, day ahead optimization of reactive power has always been one

10 of the main focuses for secure operation of DNs. More specifically, static bi/multi-objective approaches of reactive 11 power optimization for the ADS management mainly focus on the provision of a reliable reactive power margin and 12 minimum voltage sag-swell after generation-load fluctuations [32]. Tendency for higher integration of renewable 13 DERs is another reason which makes DN managers to pay more attentions to static reactive power optimization of 14 grid. These objectives are simultaneously considered in [33] by utilizing a bifurcation theory-based voltage stability 15 methodology. Authors in [34] present a scheme for optimal dispatch of the reactive power provided by wind farms to 16 obtain the desired voltage limit at buses of a DN with the high penetration of wind power. The proposed automatic 
voltage control is applied after implementation of an adaptive clustering of network to several zones. The presented

2 clustering method has the ability to efficiently determine the accurate voltage control ranges for each of wind farms.

An optimal management method for reactive power of renewable-based DERs is proposed in [35] in which DERs deliver spinning reserve to transmission grids based on two different models of information gap decision theory; while

5 the control of their corresponding active power is accomplished by the ISO, and the DN operator attempts to manage

6 the uncertainty of the reserve power. This method can considerably enhance the interactions between transmission

7 networks and DERs. In [36], the authors present a two-stage daily Volt/Var management approach in DNs using feeder

8 capacitors and substation capacitors joined with OLTCs. In the first stage of Volt/Var management, a dispatch schedule

9 for the feeder capacitors is specified based on reactive power heuristics. In the second stage, an optimization method

10 is utilized to define the dispatch schedule of the substation devices considering the control actions of the feeder's

11 capacitors. Then, the reference voltage at the point of secondary substation bus as well as the transformer tap limits

12 are improved by which the model adjusts to fluctuating load conditions. Interactions and information exchange in 13 ADSs are shown in Fig. 4 and Fig. 5, accordingly [37].

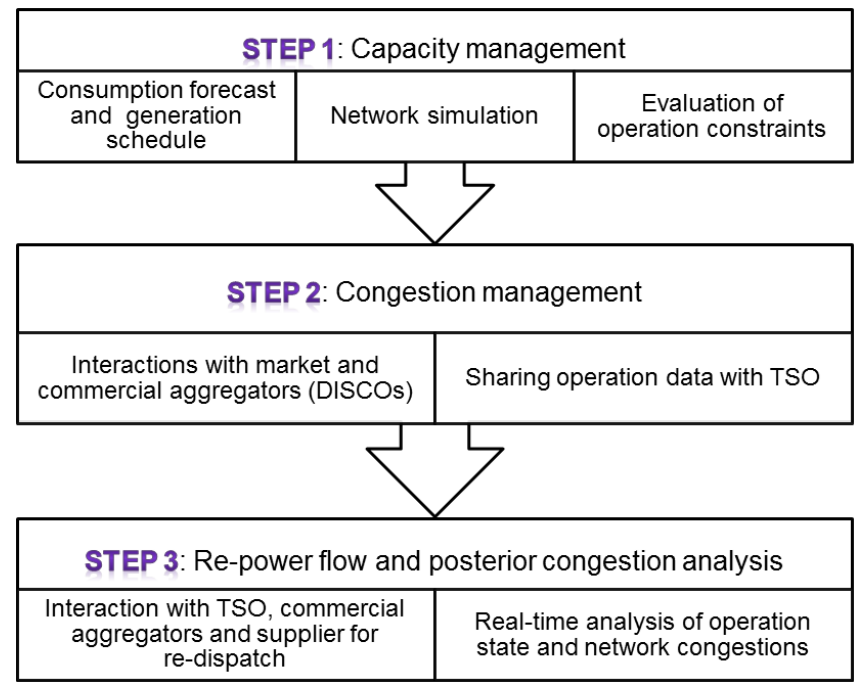




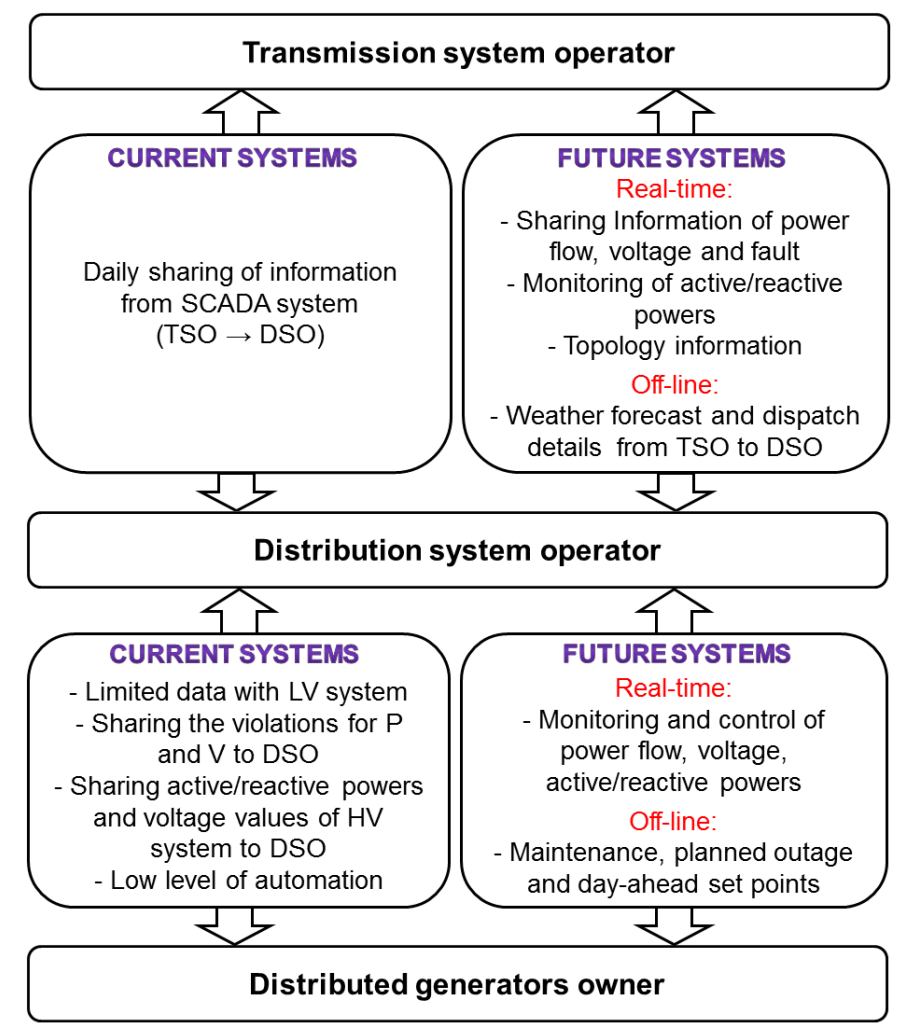

Fig. 5. Current and future data exchange of DSO with TSO and markets in ADS

\section{B. STATIC MULTI-OBJECTIVE OPERATION OF GRID}

4 In this subsection, multi-objective approaches of ADS operation is studied. Obviously, operation methods with

5 pure focus on reactive power control are not efficient for implementation in practice from operational viewpoint.

6 However, some of these objectives have been emerged as the result of significant changes of grid operation during recent years along with the involvement of renewable resources, ES systems and electricity market changes. One of

8 these objectives is investigated in [38], where a static approach for minimizing the power curtailment of dispatchable

9 DGs is considered as the main objective to remove voltage limits violations. Centralized control of active/reactive

10 power, OLTCs, shunt capacitors, and remote switches are employed as main tools to reach this goal. Reducing the

11 number of switching operations of OLTC tap and shunt capacitors, as well as maintenance costs, are considered as

12 other weighted factors in the objective function. In [39], the Volt/VAR and power loss management using DG units

13 and VAR compensators are investigated using a decentralized approach. The proposed methodology firstly divides the

14 DN into several areas with the individual Volt/VAR schemes. It is presumed that each zone is operated by a different

15 DISCO. Then optimal reactive power set point for controlling units existing in each of the areas are determined to

16 obtain the best DN operating point with the minimum power loss.

17 In [40], uncertainties of PV units and loads are modeled as the main objects of voltage control in ADS while 18 minimizing the active power loss. To this end, a robust voltage control based on the scenario generation and reduction 
for the forecasted power of renewable units and loads is proposed which controls the reactive power of DG, continuous compensator and switching capacitors. The proposed method is validated for the worst scenarios of maximum generation and minimum load in the over-voltage situation and minimum generation with maximum load in the undervoltage scenario. Monte-Carlo simulation is applied to verify the robustness of proposed approaches. The voltage regulation for ADS based on the Nash equilibrium in game theory with the participation of power suppliers, active customers and the DSO (i.e. the owner of the DN and the passive DGs and loads) is formulated in [41]. In this work, the DSO determines the voltage of buses, the reactive power of DGs and energy price for each player, while maintaining the secure operation of DN. In addition to the main objective of voltage profile control, this problem is modeled as a min-max optimization problem in which suppliers tend to maximize the pay-off, active loads want to minimize the purchasing payment, and the DSO objective is to reach an optimal ADS operating point with the

11 minimum power loss. Recently, application of power electronic devices for improvement of power quality in ADSs

12 has gained more attention. However, this research topic needs more investigation, and [42] provides a study on the 13 employment of power electronic transformers to reach more flexibility for power quality improvement. Comparing

14 to the traditional DN transformers, the power electronic based transformers provide additional characteristics as a

15 power quality controller. Simulations considering unbalanced three-phase loads, DN with the high amount of harmonics, frequency flicker, and voltage dropping are carried out to verify the effectiveness and applicability of the proposed control strategy using the proposed transformers.

In addition to static methods of technical operation and power quality improvement in ADSs, a considerable amount of studies has been done by dynamic approaches. These dynamic methods can be carried out by the hourly scheduling of grid topology and devices existing in the DN or transient evaluation and control of DN performance.

\section{C. DYNAMIC RECONFIGURATION MANAGEMENT OF GRID}

Dynamic reconfiguration of DN is a novel concept which has attracted more attentions after formation of smart grids which employ higher levels of automation and monitoring in DN operations. Without any doubt, high speed of information exchange and remote control of grid are two valuable potential benefits which smart grids have provided for DN managers.

To this end, an innovative dynamic EMS for cooperative interactions of an ADS which includes several interconnected MGs is proposed in [43] in addition to the formation and management of a group of MGs. The presented methodology considers the ADS in the superior level and MGs in the inferior level to form a bi-level optimization problem. This formulation obtains compromised solutions in terms of the DN adaption to high penetration DERs, 
voltage profile, power loss, energy utilization in the MGs and finally the economy of both the DSO and MGs. In order to proceed with such a structure, the interactions among the participants are first classified into those between DSO and MGs (achieved by a bi-level programming), and then the interactions between the MGs (managed as an interactive energy game matrix). Moreover, the concept of expanded ES systems using dispatchable capacities and controllable DGs is developed and joined into the EMS. The outline of EMS in overall structure of the ADS is depicted in Fig. 6.

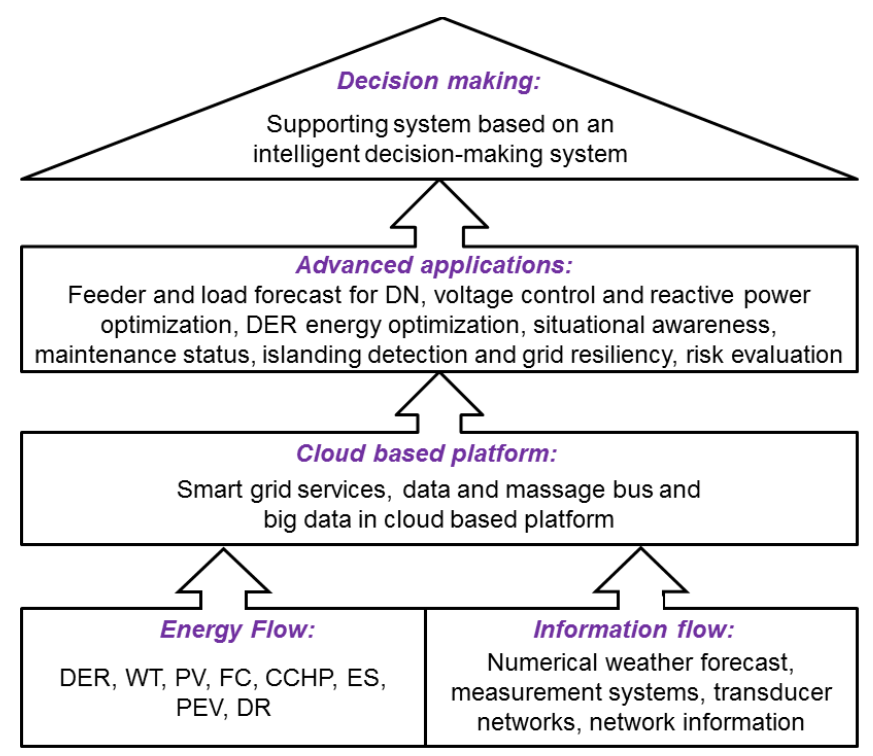

Fig. 6. Necessary structure for formation of an advanced EMS in ADS

The reconfiguration scheduling of grids is another approach which has been adopted in a number of studies to achieve the optimal technical-based operation of ADSs with the aim of reaching the desired levels of operation indices. In [44], the potential of DN reconfiguration is investigated to improve DG hosting capacity in both of static and dynamic situations. In case of the static situation (seasonal/yearly basis), the network reconfiguration should be accomplished during the planning stage for a different number of DG sites; while in the dynamic analysis remotely

11 controlled switches have been utilized to increase the DG hosting capacity as an ADS management scheme and to remove grid congestion in real-time operation. Moreover, an efficient technique for breaking down the large size of

13 the problem, which results from considering a large number of scheduling periods, is proposed in this study. Active

14 power capacity and power factor of DG units, the amount of DGs power curtailment, active/reactive power of substations connected to the upstream network as well as on/off status of line switches in the static/dynamic 16 reconfigurations are considered as the means to reach the optimal operational point. In comparison with this work, 17 utilization of remotely controlled switches to tackle thermal overload obligation of transmission lines in DN is addressed in [45]. In fact, these switches are employed to minimize the power curtailment of non-firm DG units. The authors extensively investigate the problems and present an outline for the selection of DGs, which are responsible 
reconfiguration and the DR in the form of an hourly day-ahead scheduling is provided in [46] to reach the minimum power losses and voltage deviations while maximizing thermal charging margin of the branches. This is achieved through a multi-objective approach. A sensitivity analysis based on variations of customers' participation factor and offering prices in DR procurement is implemented in this study.

\section{D. DYNAMIC POWER LOSS AND VOLTAGE PROFILE MANAGEMENT}

The power loss and voltage profile improvements can be considered as the most vital technical indices for the management of ADSs because their direct influences on the operation cost and satisfactory level of end customers. Regarding the dynamic operation of DNs, [47] implements a multi-objective optimization algorithm to minimize power loss, voltage deviation, and peak-valley difference. This research schedules the power generation of two DGs as well as the interaction power of three MGs at common power coupling point in a distribution system. The paper separately provides results for the optimization of each objective as well as obtaining a Pareto-front of non-dominated solutions. Moreover, it is demonstrated within the paper that the proposed method can guarantee the desired profile

13 for the voltage of buses. A hybrid optimization algorithm as the combination of particle swarm optimization and bacterial foraging algorithms is adopted to obtain the optimal solutions.

Authors in [48] take into account the coordinated application of OLTC, SVCs, and DG reactive power as efficient reactive power control tools for a day-ahead operation scheduling of an ADS. Besides the minimization of active power losses, the voltage violation from a specified threshold is considered as the second objective function by defining a penalty function. Dynamic thermal rating is presented in this research to achieve the desired level of network losses and voltage profile while the real-time line thermal limit is being considered in the constraints. In this study, the Q/V droop controller technique with dead-band is utilized to regulate the reactive power intake or provision of DGs. In addition, operations of OLTC, SVC, and curtailment of DG units are investigated within the case studies for different values of DG penetration and objectives. Moreover, this research proposes a voltage connection point based on local and central regulating strategies for the specific voltage controllers.

A study with the similar power loss and voltage objectives is implemented in [49] in case of integration of PV units into ADSs. A method of preventing DN overvoltage based on dynamic active/reactive power droop control of a PV generation system is proposed in this paper. By utilization of the presented technique, the obtained reactive power capacity of available PV units is fully operated to prevent overvoltage before any violation of the feeder voltage from standard limits. Moreover, a novel active power curtailment approach is formulated in addition to reactive power 
methodology has the ability of increasing the installation capacity of PV units. A single objective voltage control in a DN is studied in [50] in which authors firstly develop a novel approach for dividing the grid into a number of areas. Then validation of the proposed technique is assessed by using an illustrative example. Afterward, a multi-agent management system is formulated in the framework of two proposed decentralized voltage control methods, Thévenin equivalents and top-down sweep control method. It is assumed that each zone should be regulated by means of a controller located inside each distributed ES system. Therefore, impact of the DG units on the network is indirectly measured by the controllers of ES systems. The decrease of communication costs and computation burden is considered by assuming the operating information isolation between each zone.

\section{E. DYNAMIC ES SYSTEM MANAGEMENT}

Dynamic day-ahead scheduling of ES systems can benefit the ADSs in several technical operation aspects. The ES units can offer reliable local backup power for end-consumers while their tight proximity to consumers ensures the availability of supply in the event of an outage. In addition to improving the operating indices like power loss and

13 voltage profile, other eye-catching potential supports can be provided by ES systems, especially in large scale, like load leveling, peak shaving, frequency support and islanding operation of a MGs. In [51], a single objective power loss minimization is considered to determine the charging/discharging schedules of an ES device in different sizes with the presence of PV units for a residential feeder. Economic, technical and efficiency assessments of DN transformers, ES devices and the DC/AC converters are investigated in this paper to achieve more valid and precise results. This research employs dynamic programing instead of using other novel optimization algorithms, and the results confirm the applicability and effectiveness of the presented methodology in both solution quality and convergence speed.

In addition to voltage and loss improvement, scheduling of ES systems have also been investigated for other objectives as well. In [52], a review on potential applications of bulk storage systems, specifically on 1MW battery ES in Zurich grid, is provided. Three applications of this storage system in cases of peak shaving, frequency reserves and islanded operation of an MG are extensively discussed. In [53], simulation and experimental results of application of a novel procedure for charging/discharging scheduling of a battery ES system are reported. They utilize actual grid data to control an ES system with the objectives of power curve smoothing, peak load shaving and voltage regulation of a distribution transformer. Peak shaving is considered as two different objectives for optimization (i.e. including cost of load and cost of state of charge) based on load forecasting methods. The optimization method reaches the optimal active power flow of the ES unit at each time interval. Results show that with the application of existing bulk 

discusses the application of a grid scale ES system for load leveling in distribution systems besides the loss reduction.

The paper explains the relation between the amount of current in DN lines and power loss reduction to demonstrate potential value of peak-leveling for long-term loss reduction. Moreover, a quantitative survey is developed to investigate the possibility of loss reduction for situations in which the load of DN is shifted during time horizon, but not reduced in quantity. In addition to load leveling using an ES system, different factors affecting loss reduction are studied in this paper. Additionally, some specifications of ES including charge/discharge ramp rate and Ampere-hour capacity for the case of load leveling are analyzed. Increasing the DN capacity is one of the indices which is improved as the result of load leveling in this paper.

\section{F. DYNAMIC MANAGEMENT OF ACTIVE/REACTIVE POWER CONTROLLERS}

During recent years, advances in manufacturing technology of power-electronic devices have reached a remarkable growth. With the provision of less expensive types of these devices for DN applications, their presence in ADSs has

13 experienced a rapid growth accordingly. The most prominent applications of these devices are active/reactive power controllers. To this end, authors in [55] develop a minimization method considering square of the voltage error and power loss using the LPC in DN. In fact, LPC which is connected to the adjoining feeder in mesh configuration of ADS can effectively control voltage fluctuations of the grid. In fact, LPC can attain several power quality improvements such as grid voltage control when incorporating DGs, balancing control of DN feeder loadings and rapid compensation of voltage sags. Reference [55] presents a novel method to apply local voltage information and the determined LPC control coefficients, which are related to optimal operation of LPC, for the operation of LPCs. Three control methods of ADSs, including approximation of optimal operation, distributed control and determination of control coefficients, are extensively investigated, and finally a simulation model of ADS with integration of LPC based on the technology of back-to-back converter is developed. Considering the high attention of researchers to Volt/VAR management of ADSs and MGs with high penetration of DGs, the traditional regulation devices cannot provide the required efficiency in case of real-time regulation [56]. However, soft open points (SOPs) as flexible power electronic devices can be employed for a continuous reactive power adjustment. With the cooperation of SOP, OLTC and capacitor bank, a novel Volt/VAR dynamic scheduling of ADS is proposed in this paper. To this end, the proposed Volt/VAR control has the ability for minimization of operation costs (i.e. power loss and cost of switching) and the voltage deviation. The overall switching costs during the operation horizon of ADS include the switching cost of 
non-convex mixed-integer non-linear problem is transformed into a mixed-integer second-order cone optimization model to be more efficiently solved.

\section{G. TRANSIENT CONTROL AND OPERATION OF GRID}

In addition to day-ahead operation scheduling of DN, transient improvement of stability and power quality of DNs

5 is another vital research topic because of recent high penetration of renewable DERs. Because of the nature of transient

6 stability, most of the studies related to this topic focuses on controlling approaches of Volt/VAR devices; however, some researchers study this problem by active power control of DGs or employing fast response DR units. To this end, the utilization of voltage source converter associated with DGs for reactive power provision in ADS aimed at transient applications is proposed in [57]. Similar to [39, 50], a decentralized methodology of Volt/VAR control is proposed in this research; in which the DN is divided into several zones with separate regulation schemes. In other words, actively managed DGs are incorporated with the Volt/VAR control approach of DNs. This management of DG units in multilayer decentralized Volt/VAR control is joined with other available controllable devices such as distribution static synchronous compensators (STATCOMs), shunt capacitor banks and OLTCs. Each zone can contain several subzones as well. A tariff based payment method is adopted to reimburse the owners of DG units for reactive power provision besides the active power. Coordination of DG units and reactive compensation devices in a zone, switching DG units to voltage reference mode without triggering deep voltage sags/swell/transients and suggesting a zonal-based voltage profile regulation besides the local power loss minimization are the major findings of the paper. Researchers in [58] specifically focus on providing improvements in the application of OLTC for Volt/VAR regulation in DNs. This research attempts to embed the nonlinearities of OLTC in real-time control schemes of ADSs. Accordingly, the discrete nature of tap change, the dead-band, and time-delays as the main nonlinearities of OLTC are considered in the modeling of this device as opposed to researches which neglect these characteristics. Hence, the paper proposes a twostep approach by which OLTC time-delay is modeled through predictive control following the discrete nature of the tap position. At the next step, the OLTC references are created by explicitly considering the dead-band as another nonlinearity. Therefore, quantization approaches are addressed which avoid the failure of control algorithm. Moreover, the controller can estimate the accurate OLTC tap changes; thus the control costs for the DSO are accurately known and can therefore be reduced. Despite several contributions presented for transient power quality improvement and technical operation of ADSs in this paper, more research can be done in this regard specially for Volt/VAR management of DNs [59].

In [60] potential applications of a decentralized active DR aggregator, with the goal of frequency stability 
enhancement of ADSs for transient periods, are investigated. The paper tries to show that DR can be utilized as a part of both primary and secondary load frequency control in EPSs since it has high dynamic response in the case of disturbances. After comparing the centralized and decentralized versions of DR, the principles of distributed DR and technical/functional assumption related to this aggregator are explained; then, an analytical model for EPSs considering distributed DR is provided. Finally, the operation algorithm of the proposed methodology for the distributed DR is developed. Development procedure of the DR in different European countries is detailed in Table III.

Table III DEVELOPMENT OF DR IN DIFFERENT EUROPEAN COUNTRIES [61]

\begin{tabular}{|c|c|c|c|}
\hline & Spain & Italy & Germany \\
\hline Remuneration system & $\begin{array}{c}\text { - Revenue cap on operational } \\
\text { expenses with specified efficiency. } \\
\text { - Profit/loss sharing scheme for new } \\
\text { investments valued on the basis of } \\
\text { standard unit costs } \\
\text { - Allowed new investments and } \\
\text { network-related operation and } \\
\text { maintenance costs evaluated } \\
\text { annually with reference network } \\
\text { model }\end{array}$ & $\begin{array}{l}\text { - Price cap on operational } \\
\text { expenses with specified } \\
\text { efficiency. } \\
\text { - Regulatory asset based } \\
\text { on historical revaluated } \\
\text { costs }\end{array}$ & $\begin{array}{c}\text { - Revenue cap on total expenditure } \\
\text { with specified efficiency. } \\
\text { - Benchmarking over total } \\
\text { expenditure using book values }\end{array}$ \\
\hline Regulatory period & 6 years & 4 years & 5 years \\
\hline $\begin{array}{lr}\text { Financial incentives } \\
\text { for quality of service } \\
\text { and losses } \\
\text { performance }\end{array}$ & Targets with premiums and penalties & $\begin{array}{l}\text { Targets with premiums } \\
\text { and penalties }\end{array}$ & $\begin{array}{c}\text { Targets with premiums and } \\
\text { penalties }\end{array}$ \\
\hline \multirow[t]{2}{*}{$\begin{array}{l}\text { Active management of } \\
\text { grid by DSO allowed }\end{array}$} & Not explicitly & Not explicitly & $\begin{array}{c}\text { - Tariff } \\
\text { - Incentives/interruptible loads. }\end{array}$ \\
\hline & France & GB & Sweden \\
\hline Remuneration system & $\begin{array}{l}\text { - Revenue cap on controllable } \\
\text { operational expenses with specified } \\
\text { efficiency. } \\
\text { - Return on revenue for capital } \\
\text { expenditure and non-controllable } \\
\text { operational expenses, based on real } \\
\text { accounting value. }\end{array}$ & $\begin{array}{l}\text { - Output based regulation } \\
\text { - Total expenditure } \\
\text { incentive mechanism } \\
\text { based on the } \\
\text { performance in relation } \\
\text { to a set of output } \\
\text { categories }\end{array}$ & $\begin{array}{l}\text { - Price cap on controllable } \\
\text { operational expenses with } \\
\text { specified efficiency. } \\
\text { - Return on revenue to capital } \\
\text { expenditure and non-controllable } \\
\text { operational expenses. } \\
\text { - Planned investments in the } \\
\text { regulatory period are included in } \\
\text { the regularity asset based on } \\
\text { standard costs. }\end{array}$ \\
\hline Regulatory period & 4 years & 8 years & 4 years \\
\hline $\begin{array}{l}\text { Financial incentives } \\
\text { for quality of service } \\
\text { and losses } \\
\text { performance }\end{array}$ & Targets with premiums and penalties & $\begin{array}{l}\text { Incentive adjustments } \\
\text { within the allowed } \\
\text { revenue formula }\end{array}$ & $\begin{array}{c}\text { Revenue cap adjusted annually } \\
\text { based on actual costs versus a } \\
\text { reference level }\end{array}$ \\
\hline $\begin{array}{l}\text { Active management of } \\
\text { grid by DSO allowed }\end{array}$ & $\begin{array}{l}\text { Not explicitly. Only critical peak } \\
\text { pricing regulated tariffs }\end{array}$ & $\begin{array}{l}\text { Innovation trials with low } \\
\text { carbon network fund and } \\
\text { innovation stimulus } \\
\text { funding. }\end{array}$ & Not explicitly \\
\hline
\end{tabular}

9 In [62], transient performances of the ADS under both standalone and grid-connected conditions for voltage and

10 frequency response characteristics are studied. This paper creates a complete electromagnetic model of ADS involving

11 the medium voltage local DN that is linked to the upstream bulk transmission system. Corresponding results of this 
technique confirm the operating feasibility of ancillary service and economic dispatch to both the utility and transmission grids. Specifically, the ADSs ensure the ability of network for the transition from the grid-connected to island-mode with minimum transients. Moreover, the ADSs have the ability of procuring and deploying contingency reserves for frequency control, and also provision of reactive power by the use of fast response battery ES systems and dispatchable DERs.

\section{MODELING AND CONTROL DEVELOPMENT OF ADSS}

In this section, a review of novel ideas for modeling of ADSs and developed methodologies of management and communication for the sake of automation of DNs is presented. In this regard, it illustrates recent studies on evaluation and analysis of ADS operation indices, mathematical modeling and analysis of DN software tools, and finally, the development of approaches for optimal control and automation in ADSs.

\section{A. ASSESSMENT OF OPERATION INDICES OF GRID}

Electrical DN operating indices can be considered as a set of values which can manifest the current/future operating

13 situations of grid from different aspects. The most important indices in distribution section are the reliability capability

14 of grid for secure power supply; however, there are a number of indices that have been formulated for the safe operation 15 of network from DSO's viewpoint. It should be mentioned that some operating indices of the grid are changing 16 continuously, which is partly because of the integration of new DERs in DNs or new regulations of power markets. 17 Authors in [63] present a reliability evaluation of ADS considering ES units and real-time electricity pricing. The paper models a DN including MGs and ES at the first stage in which the output power of DGs is calculated based on the method of generalized capacity outage tables. Then, the Monte-Carlo simulation is applied to perform reliability evaluation. Different sizes of ES are analyzed for this task. In other words, the influences of DGs, ESs, and real-time pricing based management strategy of ESs on the DN reliability are investigated. System average interruption frequency index (SAIFI), system average interruption duration index (SAIDI) and expected energy not supplied (EENS) are calculated as reliability indices of the ADS to depict the current condition of the grid. Three scenarios are considered based on the presence and amount of ES units. In the first one, some of the load points of the MG are shed due to the failure of components without the presence of ES units. In the second scenario, the energy stored in the ES units can fully meet the shed load points; however, in the third scenario, ES can only partially meet the load demand of the MG.

Reference [64] presents the experimental experiences of Unión Fenosa Distribución in PRICE-GDI for evaluation of loss, voltage, Volt/VAR indices in a pilot project after the integration of DG units in ADSs. This paper also describes 
key outcomes regarding the control of voltage profile in low/medium voltage grids with DERs (i.e. DG units, DRs and ESs). The offered solution is based on EMS, where power and voltage values are monitored in real time and the control room center is able to send set points to power electronic devices and generators which participate in a centralized voltage control. Optimal set points are calculated by a voltage control procedure, established by the Comillas Pontifical University. This methodology is applied to three cases. The first one is a real medium voltage DN including DGs with the capability of connecting to medium/low voltage networks and a STATCOM device. The second case is a LV network located in a laboratory, where a DG and STATCOM are coupled to investigate the Volt/VAR functionality in LV grids. The last scenario is the study of DN by University of Seville which is capable of investigating the performance of a medium voltage grid with several types of generators and loads to overcome the technical and regulatory barriers of these scenarios.

Authors in [65] investigate problems caused by power electronic devices used in renewable-based DERs, and

12 formulate a probabilistic index to quantify the controllability of voltage of buses and current in the lines of DNs including single/multi-MGs. A new index is formulated to optimally cluster the ADSs into a multi-MG network with optimized degrees of controllability, reliability and supply-security indices. In order to evaluate the robustness of the offered design and the influences of interconnected various distributed DGs and reactive sources, several sensitivity analyses are carried out. SAIDI, SAIFI, and momentary average interruption frequency index (MAIFI) using annual outage duration, annual failure rate, and momentary failure rate are calculated and considered as reliability indices of multi-MG systems; while the supply-security factor ensures the adequacy of active/reactive powers for MGs.

In [66], the authors implement a risk assessment task for transmission systems considering the influences of ADSs.

As opposed to the previous studies which completely ignore the characteristics of DNs in the modeling of transmission buses, this paper considers the ADSs as a potential active system with the presence of DGs. Therefore, ADSs are modeled as a power supply in some time periods that can send power back to the upstream transmission network in addition to meet local load demands. Based on the proposed hierarchical evaluation of the DN on risk assessment of transmission network, DGs are modeled as a supply for critical loads through re-dispatching during contingency (i.e. the islanded mode in this paper). In order to ensure the required high-reliability level for DN customers, the factor of available supply capacity is utilized. Moreover, an iterative evaluation procedure between DN and transmission system

27 is implemented to develop the risk indices considering detailed structures of the ADS. Furthermore, the influence of some indices on system risk evaluation, such as location, outage probability, dispersion and capacities of DGs, is studied. EENS, the probability of load curtailment, expected frequency of load curtailment and a new severity factor are considered as reliability indices for transmission systems. In [67], authors use the Monte Carlo simulation to assess 
reliability index of ADS for low/high levels of DG penetration. A two-case programing is formulated in which the load shedding strategy is modeled when there is an imbalanced generation-load situation. As opposed to the traditional failure-effect approaches for DNs reliability evaluation, which study the effect of a component failure and its consequences on loads and then calculate the reliability indices such as SAIFI and SAIDI, this work analyzes the condition of DG high penetration with normal operation of all components, taking consideration of the possible power shortage caused by chaotic output of renewable-based DGs.

Another reliability assessment method based on the concept of capacity credit of DERs is provided in [68]. In EPS terminology, the term "capacity credit" is considered as a quantifying metric for the involvement of a unit to the adequacy of generating system. In addition, a general probabilistic-based model of DR is presented so that the end user behaviors are discriminated by two coupling procedures: inter-temporal impact and instant response. The sequential

11 Monte-Carlo simulation is also adopted to improve the computation efficiency. The uncertainties related to the 12 behaviors of end customers are modeled by a hybrid possibility-probabilistic formulation that characterizes both 13 specific characteristics and generic regularity of DR. Besides, a novel index for evaluating the role of ADSs in bulk 14 ancillary services markets is proposed in [69] considering different regulatory structures for transmission and DN 15 market interactions. This procedure estimates the DNs capabilities to support network stability, by employing a hybrid representation of high/medium voltage substations and their relevant DNs with a GIS based clustering method. Big data technology as another potential tool has been employed in [70] in order to evaluate an operational reliability index in ADSs, and predict the future reliability value of grid from the current state of the system. To this end, this paper

19 firstly analyzes the substantial influencing factors of reliability indices by the parallel association-rule mining 20 algorithm. Then, these factors are used as input variables of an evaluation model based on the artificial neural 21 network. Finally, forecasted operational reliability values are obtained using the developed model and real-time data.

22 Input data for training and test of the neural network include the historical operational status and current states of DN devices and equipment, outage condition and time of units, geographic and weather information as well as image and

24 field environment data.

\section{5}

\section{B. POWER FLOW AS A TOOL FOR GRID PERFORMANCE EVALUATION}

Obviously, several algorithms are needed for the numerical analysis of ADS performance. Load flow and economic load dispatch are among these tools which have been the subject of a large number of research publications in DNs along with the formulation and development of ADSs. These algorithms are essential for future planning/expansion of DN as well as the determination of the best operating point of existing grids. In this respect, [71] presents an efficient 
algorithm to handle P-V nodes (i.e. DG connected nodes with the constant voltage control) based on loop analysis combined with the forward/backward sweep power flow. Considering the fact that the main part of proposed hybrid power flow is remained as same as forward/backward sweep power flow, this algorithm is suitable for weakly meshed DNs; and also appropriate to deal with networks containing a large number of P-V nodes with varying branch R/X.

Another attempt to adopt the traditional power flow to the new structure of ADSs is accomplished in [72] where a multi-temporal power flow algorithm is proposed to assess DER hosting ability of an ADS. In order to compensate the inaccuracy of some convex relaxation based power flow methods during periods of intensive DERs production, a number of linear constraints are added in the power flow formulation to guarantee an exact relaxation. Comparing to the literature, formulation of power flow in multiple-time-scales can better evaluate functions of storage systems, due to the temporal dependency of storage decision variable within an ADS in terms of charging and discharging

11 procedures. To this end, a three-day period of simulation is implemented in this paper to reach at least one full 12 charging/discharging cycle of the storage units. Utilization of PV units for different capacities and also conditions with/without storages is investigated to confirm effectiveness of the proposed methodology in case of reaching the

14 maximum line current limits. In [73], the problem of unbalances in operation of ADSs is analyzed using three-phase

15 DN load flow based on the symmetrical components. Besides modeling the fluctuated natures of WTs and PV units, load model of center-tapped transformers, as one of the main novelties of the paper, is involved in the proposed formulation. In order to validate the effectiveness and applicability of the presented algorithm, it is simulated on IEEE 8500-node test feeder as the largest IEEE PES distribution test system with 1177 distribution transformers connected to 1177 loads.

In [74], authors study the problem of approximate solutions for the nonlinear equations of the active/reactive power; which refer to the generation-demand balance in DNs. The paper presents the required conditions for the existence of a practical solution for power flow equations. Then a linear formulation to obtain the approximate active/reactive power value for demands of the P-Q buses is proposed. Instead of aiming at reaching an exact approximation of loss value, solutions with tolerable error bounds are obtained which are trustable for generic DN topology and branch impedances. It is proved that the proposed approximations and their corresponding analytical error bounds are linear in reference to active/reactive powers at the buses. Moreover, results show that it is possible to consider the presented method for $\mathrm{P}-\mathrm{V}$ buses by adding some manipulations. A novel methodology for backward/forward sweep based power flow in DN is proposed in [75] where a direct process of $Z_{\text {bus }}$ matrix and parameters of lines are modeled. With the aim of fixing voltage magnitude at the specific buses of a network with multiple P-V buses, an approximate iterative solution is utilized. In fact, the modification of bus voltages is established 
based on the grid data and reactive power injection of units; and it is applicable to both the radial/weakly meshed DNs, and transmission grids.

Reference [76] presents an optimal power flow to assist the DSO in case of economic dispatch of DER units. Its main contribution includes the utilization of voltage control to satisfy network security requirements and economic objectives, incorporation of unbalanced $\mathrm{DN}$, and consideration of the structure and economics of energy market for the ADSs. Previous methods of the voltage management in traditional DNs reduce load demand of the feeders and reach energy savings, while the approach in [76] can meet physical considerations of the ADS operation so that the voltage-dependent customers can optimally attain economic objectives of the market. In other words, operational constraints and economic requirements of the optimal power flow are simultaneously incorporated in this research. Another method for optimal power flow of ADSs is proposed in [77] using cutting-plane-relaxation. Considering

11 significant attention in branch flow models based on second order cone programming, an investigation on different 12 necessary assumptions and conditions for ensuring the relaxation exactness of the method is provided at the first stage. 13 Then, the cutting-plane technique is applied to overcome the exactness challenges of this model for ADSs especially 14 for networks with high penetration of renewable DERs. Afterwards, in order to adapt these conditions to the research 15 objectives, a total power-loss-cut is introduced to ensure the conic relaxation exactness. Furthermore, the authors of 16 [77] propose a leaf branch current-cut method which can support the algorithm to avoid the relaxation inexactness of 17 second-order cone programming in some leaf branches. Finally, some demonstrations of cutting-planes are presented 18 to guarantee that the proposed model of relaxed optimal power flow reach acceptable degree of relaxation exactness 19 and optimality, regardless of considering the power loss as one of the objectives.

\section{NOVEL MODELLING APPROACHES OF GRID}

Along with the significant changes of grid during recent years, some modeling approaches of elements in ADSs need to be modified. Moreover, some investigations are required for the modeling of ADSs to analyze current state and deficiencies of network. In this regard, an extensive research on analysis, modeling and control methods of integration of DERs into the isolated and grid-connected DNs using voltage/current source converters is provided in [78]. It mentions several challenges related to high penetration of DGs and employing novel digital devices like phase measurement units for monitoring and state estimation of ADSs. These challenges are also investigated in [79] in more detail. The survey in [79] extensively discusses the structure design problems, deficiencies of real-time measurements and measurement configurations, and also explains the difficulties of state estimation in future ADSs. In [80], a new 
presented. In fact, in addition to the electrical and fluid mechanical modeling of CAES, the potential abilities of CAESs

2 as a flexible DR in city districts are assessed. Utilizing the results of an offline day-ahead scheduling for the purposes

3 of operation based planning, size of compressor and storage is determined at small/medium enterprises and the industry

4 level. Finally, the flexibility of the given small CAES (in the kW range) for industrial applications is evaluated. One

5 of the most prominent outcomes of the presented method is that it can be applied when there are no consumption

6 measurements to model the air demand. However, results demonstrate that this system cannot provide considerable

7 financial savings by harvesting the market price variations.

8 In [81], a new formulation and modeling of centralized thermal overload management with a significant amount of

9 DGs in ADS is proposed. This study uses some of the control variables of a network including the active/reactive

10 powers and on/off status of DG units, the status of breakers, tie switches, and remotely controlled sectionalizing

11 switches to minimize the curtailment amount of dispatchable DGs, thus managing the thermal overload of branches.

12 Besides, a multi-objective function is developed which reveals the DSO's penchant for economic switching. It means

13 that revenue saving as a result of generation curtailment reduction beats the cost of switching actions. The primary

14 objective of [82] is to offer an analytical method aiming at the determination of the energy efficiency effects on

15 electricity customers. The paper investigates the reduction in energy consumption of the residential sector by home

16 appliance replacements. Moreover, implementation of the large-scale study in this paper demonstrates some reductions

17 of the maximum/average/minimum consumption patterns before efficiency improvement. The presented concept gives

18 insights into the potential and costs/benefits of the energy efficiency. Hence, it is suitable for the economic and long-

19 term statistical studies. Additionally, the results provided by this study can support the electric utilities for better

20 efficiency management of the development programs within their communities.

\section{D. COMMUNICATION AND CONTROL REQUIREMENTS OF ADSS}

22 Communication and control requirements of ADSs in both decentralized/agent-based management systems are 23 other important topics which are investigated in this review paper. Fig. 7 shows the schematic diagram of controlling 24 procedures of the ADS. 


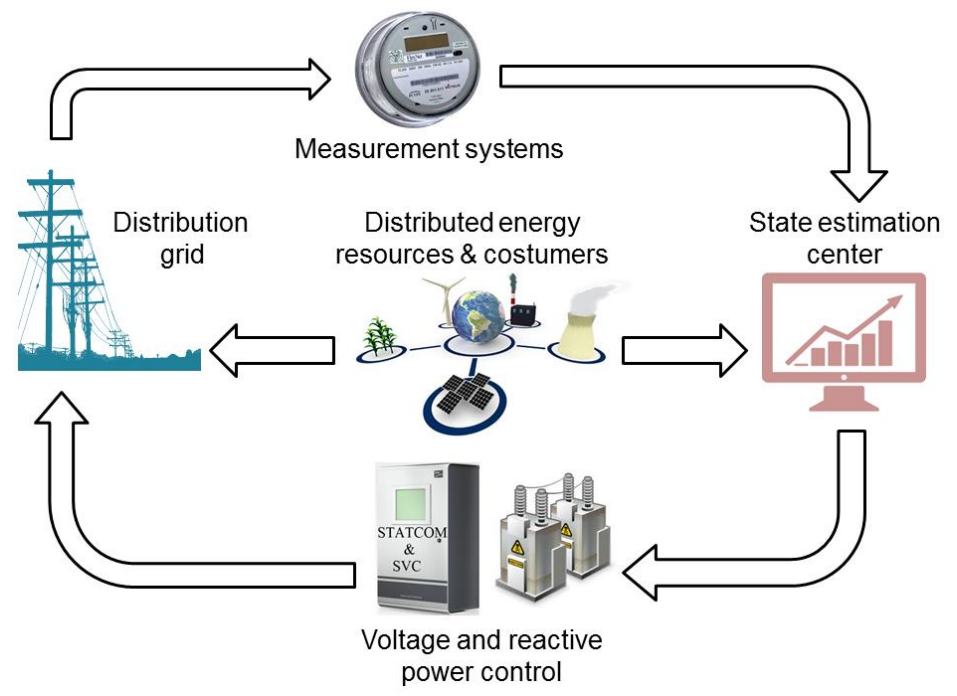

Fig. 7 Structure of controlling devices in ADS

3 With the formation of smart grids, communication aspects of operation and control of DNs have attracted more noteworthy attentions. These considerations for clustering of multiple MGs are studied in [83] to form an effective control paradigm in the smart-grid framework. The presented methodology facilitates systematic and organized clustering of a DN into several virtual MGs with the optimum communication requirements while considering the distributed reactive sources, distributed ES units, characteristics of DG units and power quality aspects. Moreover, this new strategy provides a robust infrastructure for smart DN operation for example, self-healing and optimized operation by using virtual MGs as building blocks in future DNs. Considering the fact that there is no relationship between the

10 planning features of the communication system and DG ownership, the paper highlights the necessity for the 11 communication infrastructure to cover both utility-owned and customer-owned DGs to guarantee a broad access to strategic generators and loads.

Obviously, segmenting DNs to several clusters is a gate for decentralized and multi-agent based control of 14 distribution grids in the framework of ADSs. In this regard, [84] firstly presents the requirements of DSOs in restructured power networks and then discusses the importance of the islanded operation of ADSs which are involved

16 with a large amount of DERs. Afterwards, it proposes a multi-agent based controller to stabilize voltages and frequency 17 of the ADS after the transition of network from the grid-connected to the islanding mode of operation. In order to validate the applicability of multi-agent based controller, a real-time simulation is implemented.

19 Four major sections of this methodology comprising of agents, physical power system components, agent control 20 logic, and agent communication are extensively described in this research. The platform of real-time simulation based 21 on the real-time coordination of digital simulator and the multi-agent software platform is developed. Another attempt 22 for the development of ADS using multi-agent based control concept is studied in [85]. During the proposed procedure 23 of multi-level cluster control, the opportunity will be provided for grid operator to develop a control function down to 
local level. This scheme applies the conventional horizontal idea of ENTSO-E to each of cluster areas in case of secondary control function, which implements the secondary control functionalities in both vertical and horizontal forms. As a result, all generating units can be adjusted to reach the energy balance within their responsible cluster area by combining the clustering and multi-level hierarchical control strategy. Employing this top-down control approach, DG units can be integrated more flexibly and adaptably into the grid. Besides, the opportunity of coexisting with current conventional control of grid is another highlight of this control strategy.

In [86], a multi-agent control of ADSs is implemented for the application of load restoration. In this fully decentralized method, customers' priority and expert system rules (e.g. each agent can execute a rule with respect to the faulted zone and its location) are considered to permit the agents to execute their tasks autonomously in addition to operational constraints of both normal and restored feeders. In comparison to previous literature, key contributions of this study include the possible application of one uniform type of agents to simplify the implementation in practice, reduction in the number of agents due to the allocation of agents only to feeders, fully decentralized feature of agents' operation in response to fault location, and a backup agent to increase system reliability.

In [87], a practical implementation of this agent-based control on a DN is reported in addition to the presentation of an overview on decentralized control of ADSs. Management of voltage deviation, DN energy imbalances in intraday market, and congestion in the real-time operation of the DN are main objectives of this study.

Finally, a summary on issues studied in this review are provided in Table IV. Since there are a wide range of valuable papers and sub-topics which have not been covered in this study, the references listed in Table IV serve only as examples of the relevant studies.

TABLE IV SUMMARY OF LITERATURE REVIEW FROM DIFFERENT ASPECTS

\begin{tabular}{|c|c|c|c|c|}
\hline Ref. & Year & $\begin{array}{l}\text { Area of } \\
\text { research }\end{array}$ & Objective & $\begin{array}{c}\text { Solution algorithm/ Software \& } \\
\text { toolbox }\end{array}$ \\
\hline [1-4] & $\begin{array}{l}2008 \\
2012- \\
2013\end{array}$ & Intro & $\begin{array}{l}\text { A brief discussion on trends and concepts behind the advent } \\
\text { of ADSs }\end{array}$ & N/A \\
\hline$[5]$ & 2014 & Intro & $\begin{array}{l}\text { To sheds light on missing aspects in current regulation, and } \\
\text { recognizing DSOs as regulated monopolies in Europe }\end{array}$ & N/A \\
\hline$[6]$ & 2013 & Intro & $\begin{array}{l}\text { To introduce the basic concept of ADSs, research tendencies, } \\
\text { the differences between traditional DNs and ADSs and the } \\
\text { corresponding research results }\end{array}$ & N/A \\
\hline [7] & 2016 & Intro & $\begin{array}{l}\text { A review on models, methods and future researches in case of } \\
\text { optimal operation of smart DNs }\end{array}$ & N/A \\
\hline [8] & 2013 & $\mathrm{EM}+\mathrm{DS}$ & $\begin{array}{c}\text { To minimize operating cost of ADS through scheduling of } \\
\text { active/reactive powers of upstream bus, DERs, ESs and } \\
\text { controllable loads }\end{array}$ & Lingo software \\
\hline [9] & 2016 & $\mathrm{EM}+\mathrm{DS}$ & $\begin{array}{c}\text { Minimization of operational costs as well as power losses } \\
\text { using day-ahead power flow control and rapid } \\
\text { reconfiguration }\end{array}$ & $\begin{array}{l}\text { KNITRO software \& AIMMS } \\
\text { programming language }\end{array}$ \\
\hline$[10]$ & 2017 & $\mathrm{EM}+\mathrm{DS}$ & $\begin{array}{l}\text { Formulate active/reactive optimization problem as a mixed } \\
\text { integer second order cone programming problem }\end{array}$ & $\begin{array}{l}\text { GAMS \& Second order cone } \\
\text { programming }\end{array}$ \\
\hline [11] & 2015 & $\mathrm{EM}+\mathrm{DS}$ & Scheduling of active/reactive powers of WT, PV and ES units & Improved harmony search \\
\hline
\end{tabular}




\begin{tabular}{|c|c|c|c|c|}
\hline & & & to minimize voltage deviation and operating expenditures & optimization/ Matlab \& Coding \\
\hline$[12]$ & 2010 & $\mathrm{EM}+\mathrm{DS}$ & $\begin{array}{l}\text { Day-ahead and intra-day scheduling of DERs to reach } \\
\text { minimum generation cost for meeting a set of electrical and } \\
\text { thermal loads }\end{array}$ & $\begin{array}{c}\text { Mixed-integer linear } \\
\text { programming/ Matlab \& } \\
\text { coding }\end{array}$ \\
\hline$[13]$ & 2016 & $\mathrm{EM}+\mathrm{DS}$ & $\begin{array}{l}\text { Employing a double-horizon scheduling to minimize } \\
\text { deviations of system operation from first scheduling }\end{array}$ & $\begin{array}{l}\text { KNITRO software \& AIMMS } \\
\text { programming language }\end{array}$ \\
\hline$[14]$ & 2016 & $\mathrm{EM}+\mathrm{DI}$ & $\begin{array}{c}\text { Maximizing the expected profit of electricity retailer } \\
\text { company for buying/selling in day-ahead market and buying } \\
\text { from spot market }\end{array}$ & $\begin{array}{l}\text { Genetic algorithm/ MATLAB } \\
\text { \& Optimization Toolbox }\end{array}$ \\
\hline$[15]$ & 2017 & $\mathrm{EM}+\mathrm{DI}$ & $\begin{array}{l}\text { Study and application of transportable-electrical ES unit for } \\
\text { minimizing the cost of energy imported from the upstream } \\
\text { grid }\end{array}$ & $\begin{array}{l}\text { Particle swarm optimization/ } \\
\text { Matlab \& coding }\end{array}$ \\
\hline$[16]$ & 2014 & $\mathrm{EM}+\mathrm{DI}$ & $\begin{array}{l}\text { To minimize total emission and operational costs through } \\
\text { proper PEVs' charge/discharge scheduling }\end{array}$ & $\begin{array}{l}\text { GAMS \& MILP and NLP } \\
\text { solvers CONOPT }\end{array}$ \\
\hline [17] & 2016 & $\mathrm{EM}+\mathrm{DI}$ & $\begin{array}{c}\text { Optimal operation and management scheme for maximum } \\
\text { economic benefits of a local power company considering } \\
\text { PEV aggregators }\end{array}$ & $\begin{array}{l}\text { Monte-Carlo simulation/ } \\
\text { GAMS \& CONOPT solver }\end{array}$ \\
\hline$[18]$ & 2018 & $\mathrm{EM}+\mathrm{OC}$ & $\begin{array}{c}\text { Simultaneous management of WT and PEVs in security } \\
\text { constrained unit commitment problem }\end{array}$ & GMAS \& CPLEX solver \\
\hline [19] & 2016 & $\mathrm{EM}+\mathrm{OC}$ & $\begin{array}{c}\text { Coordinated optimal operation of the ADS while maximizing } \\
\text { profit for PEV aggregator using a bi-level hierarchical } \\
\text { approach }\end{array}$ & $\begin{array}{l}\text { Distribution optimal power } \\
\text { flow/ GAMS \& KNITRO } \\
\text { solver } \\
\end{array}$ \\
\hline$[20]$ & 2017 & $\mathrm{EM}+\mathrm{OC}$ & $\begin{array}{c}\text { Control of PEVs' charge/discharge to prevent under voltage } \\
\text { issues and flatten the load-demand profile in ADSs using an } \\
\text { autonomous communication-free system }\end{array}$ & $\begin{array}{l}\text { Fuzzy logic control/ Matlab \& } \\
\text { Simulink }\end{array}$ \\
\hline [21] & 2012 & $\mathrm{EM}+\mathrm{OC}$ & $\begin{array}{l}\text { Proposing a tariff based framework to prevent the DN } \\
\text { congestion resulting from day-ahead charge/discharge } \\
\text { schedule of PEVs }\end{array}$ & $\begin{array}{l}\text { Optimal power flow using } \\
\text { linear programming/ } \\
\text { MATLAB \& coding } \\
\end{array}$ \\
\hline$[22]$ & 2014 & $\mathrm{EM}+\mathrm{OC}$ & $\begin{array}{l}\text { Real-time operation and PEV charge/discharge scheduling } \\
\text { using an agent based EMS of ADS in a deregulated market }\end{array}$ & $\begin{array}{l}\text { IBM ILOG CPLEX } \\
\text { Optimization Studio } \\
\end{array}$ \\
\hline [23] & 2015 & $\mathrm{EM}+\mathrm{OC}$ & $\begin{array}{c}\text { Copula based modeling of PEV behaviors and controlling the } \\
\text { load demand of PEV charging using DR }\end{array}$ & $\begin{array}{l}\text { Stochastic programing in } \\
\text { GAMS } \\
\end{array}$ \\
\hline [24] & 2009 & $\mathrm{EM}+\mathrm{MF}$ & An introduction for involvement of MGs into ADSs & N/A \\
\hline [25] & 2017 & $\mathrm{EM}+\mathrm{MF}$ & $\begin{array}{c}\text { Effects of daily operating of MGs with RESs on secondary } \\
\text { DNs }\end{array}$ & N/A \\
\hline [26] & 2012 & $\mathrm{EM}+\mathrm{MF}$ & $\begin{array}{l}\text { Optimized approaches of clustering of the DNs into a set of } \\
\text { virtual MGs with sufficient self-adequacy }\end{array}$ & $\begin{array}{l}\text { Tabu search optimization/ } \\
\text { Matlab \& coding }\end{array}$ \\
\hline [27] & 2014 & $\mathrm{EM}+\mathrm{MF}$ & $\begin{array}{c}\text { Clustering approaches for ADSs into a set of MGs with } \\
\text { optimized reliability and supply adequacy indices }\end{array}$ & $\begin{array}{l}\text { Tabu search optimization/ } \\
\text { Matlab \& coding }\end{array}$ \\
\hline [28] & 2014 & $\mathrm{EM}+\mathrm{MF}$ & $\begin{array}{l}\text { Maximizing the benefit of DISCO and several MGs } \\
\text { connected to others based on framework of a system of } \\
\text { systems }\end{array}$ & $\begin{array}{l}\text { Sequential quadratic } \\
\text { programming }\end{array}$ \\
\hline [29] & 2017 & $\mathrm{EM}+\mathrm{MF}$ & $\begin{array}{l}\text { Energy management in ADSs including ES units, PV systems } \\
\text { and diesel generators }\end{array}$ & $\begin{array}{l}\text { Shuffle frog leaping algorithm } \\
\text { Matlab \& coding }\end{array}$ \\
\hline [30] & 2014 & $\mathrm{EM}+\mathrm{MF}$ & $\begin{array}{c}\text { Incorporating ADS in security constraint unit commitment } \\
\text { problem based on framework of a system of systems }\end{array}$ & $\begin{array}{l}\text { ILOG CPLEX 12.4's MIQP } \\
\text { Solver } \\
\end{array}$ \\
\hline [31] & 2009 & $\mathrm{TP}$ & $\begin{array}{l}\text { A brief introduction over technical management and power } \\
\text { quality improvement in ADSs }\end{array}$ & N/A \\
\hline [32] & 2012 & $\mathrm{TP}+\mathrm{SR}$ & $\begin{array}{l}\text { Investigating the relation of DG stability and its participation } \\
\text { level considering technical issues. }\end{array}$ & $\begin{array}{c}\text { Non-dominated } \\
\text { sorting genetic optimization } \\
\text { algorithm II/ Matlab \& coding }\end{array}$ \\
\hline [33] & 2015 & $\mathrm{TP}+\mathrm{SR}$ & $\begin{array}{l}\text { A comprehensive study on impacts of VAR optimization on } \\
\text { dynamic voltage stability and power loss minimization using } \\
\text { bifurcation theory }\end{array}$ & $\begin{array}{l}\text { Bifurcation theory and particle } \\
\text { swarm optimization/ Matlab \& } \\
\text { coding }\end{array}$ \\
\hline [34] & 2016 & $\mathrm{TP}+\mathrm{SR}$ & $\begin{array}{l}\text { Adaptive voltage management of DN using zone-division } \\
\text { based automatic reactive power dispatch of wind farms }\end{array}$ & N/A \\
\hline [35] & 2016 & $\mathrm{TP}+\mathrm{SR}$ & $\begin{array}{l}\text { Employing reactive power of DERs as well as enhancing the } \\
\text { interactions between transmission networks and DERs }\end{array}$ & $\begin{array}{l}\text { Information-gap decision- } \\
\text { making theory/ Matlab \& } \\
\text { coding }\end{array}$ \\
\hline [36] & 2016 & $\mathrm{TP}+\mathrm{SR}$ & $\begin{array}{l}\text { Network-wide control combining feeder and substation } \\
\text { controllers minimizing voltage deviations and power losses }\end{array}$ & $\begin{array}{l}\text { Particle swarm optimization } \\
\text { algorithm/ Matlab \& coding }\end{array}$ \\
\hline
\end{tabular}




\begin{tabular}{|c|c|c|c|c|}
\hline [37] & 2005 & $\mathrm{TP}+\mathrm{SR}$ & $\begin{array}{c}\text { Describing the vision for advanced distribution automation } \\
\text { and characterizing its advantages for future power systems as } \\
\text { well as their corresponding technology requirements }\end{array}$ & N/A \\
\hline$[38]$ & 2014 & $\mathrm{TP}+\mathrm{SM}$ & $\begin{array}{c}\text { To minimize the curtailment of dispatchable DGs to manage } \\
\text { violation of voltage profile using shunt capacitor, OLTC, and } \\
\text { remote switches }\end{array}$ & $\begin{array}{l}\text { GAMS \& MINLP-RC and } \\
\text { MIQCP models }\end{array}$ \\
\hline [39] & 2016 & $\mathrm{TP}+\mathrm{SM}$ & $\begin{array}{c}\text { Minimizing power loss through dividing grid into several } \\
\text { zones with individual Volt/VAR schemes with incorporation } \\
\text { of DGs and VAR compensators }\end{array}$ & $\begin{array}{c}\text { Second-order cone } \\
\text { programming/ Matlab \& } \\
\text { coding }\end{array}$ \\
\hline [40] & 2015 & $\mathrm{TP}+\mathrm{SM}$ & $\begin{array}{l}\text { Minimizing power loss using a robust voltage control be } \\
\text { means of PV and SVC }\end{array}$ & $\begin{array}{l}\text { Monte-Carlo simulation and } \\
\text { interior point method/ Matlab } \\
\qquad \& \text { coding }\end{array}$ \\
\hline [41] & 2012 & $\mathrm{TP}+\mathrm{SM}$ & $\begin{array}{l}\text { A voltage regulation technique for DSO, active power } \\
\text { generators and active load customers in the ADS based on a } \\
\text { hierarchical methods }\end{array}$ & $\begin{array}{l}\text { Nash game theory and interior } \\
\text { point method/ Matlab \& coding }\end{array}$ \\
\hline$[42]$ & 2014 & $\mathrm{TP}+\mathrm{SM}$ & $\begin{array}{c}\text { Minimization of frequency flickers and voltage dropping in } \\
\text { networks including three-phase unbalanced and harmonics } \\
\text { loads using power electronic transformer }\end{array}$ & Matlab \& Simulink \\
\hline [43] & 2016 & $\mathrm{TP}+\mathrm{DR}$ & $\begin{array}{l}\text { Energy management of MGs-based ADS incorporating } \\
\text { expanded ES system and large integration of RESs }\end{array}$ & $\begin{array}{l}\text { Rough Set Theory- } \\
\text { Hierarchical Genetic } \\
\text { Algorithm-NSGA-II/ Matlab } \\
\quad \& \text { coding }\end{array}$ \\
\hline [44] & 2015 & $\mathrm{TP}+\mathrm{DR}$ & $\begin{array}{l}\text { To maximize DG hosting capacity of ADS by reconfiguration } \\
\text { in both static and dynamic situations }\end{array}$ & $\begin{array}{l}\text { GAMS \& Mixed-integer non- } \\
\text { linear programming }\end{array}$ \\
\hline$[45]$ & 2014 & $\mathrm{TP}+\mathrm{DR}$ & $\begin{array}{c}\text { To maximize DG curtailment and thermal overload } \\
\text { management using a dynamic remote switches control } \\
\text { approach }\end{array}$ & $\begin{array}{c}\text { GAMS \& Mixed-integer } \\
\text { quadratically constrained } \\
\text { programming }\end{array}$ \\
\hline [46] & 2013 & $\mathrm{TP}+\mathrm{DR}$ & $\begin{array}{l}\text { Power loss minimization using dynamic intra-day } \\
\text { reconfiguration and demand reduction scheduling }\end{array}$ & $\begin{array}{l}\text { An iterative based procedure \& } \\
\text { coding }\end{array}$ \\
\hline [47] & 2016 & $\mathrm{TP}+\mathrm{DP}$ & $\begin{array}{c}\text { Scheduling of dispatchable DGs, MGs and tie switches to } \\
\text { minimize power loss, voltage deviations and peak to valley of } \\
\text { load profile }\end{array}$ & $\begin{array}{l}\text { Particle swarm and bacterial } \\
\text { foraging optimization } \\
\text { algorithms/ Matlab \&coding }\end{array}$ \\
\hline$[48]$ & 2015 & $\mathrm{TP}+\mathrm{DP}$ & $\begin{array}{c}\text { Scheduling strategy for OLTC, SVC, DG reactive power } \\
\text { to reach minimum peak to valley difference, voltage } \\
\text { deviation, and power loss }\end{array}$ & N/A \\
\hline [49] & 2016 & $\mathrm{TP}+\mathrm{DP}$ & $\begin{array}{c}\text { Power loss and overvoltage management using } \\
\text { active/reactive power droop control of PVs to increase the } \\
\text { PVs capacity installation }\end{array}$ & N/A \\
\hline$[50]$ & 2016 & $\mathrm{TP}+\mathrm{DP}$ & $\begin{array}{l}\text { ES scheduling for a zonal based voltage control using multi- } \\
\text { agent system structure }\end{array}$ & $\begin{array}{c}\text { Linear programming } \\
\text { technique/ } \\
\text { Matlab \& YALMIP } \\
\text { toolbox }\end{array}$ \\
\hline$[51]$ & 2016 & $\mathrm{TP}+\mathrm{DE}$ & $\begin{array}{l}\text { Economic and technical evaluation of ES scheduling for real } \\
\text { power loss reduction in a DN }\end{array}$ & $\begin{array}{l}\text { Dynamic programming/ } \\
\text { Coding }\end{array}$ \\
\hline$[52]$ & 2015 & $\mathrm{TP}+\mathrm{DE}$ & $\begin{array}{l}\text { A review on real applications of Zurich battery ES system in } \\
\text { cases of primary frequency control, peak shaving and } \\
\text { islanding operation }\end{array}$ & N/A \\
\hline$[53]$ & 2016 & $\mathrm{TP}+\mathrm{DE}$ & $\begin{array}{l}\text { ES scheduling for voltage regulation, load-demand curve } \\
\text { smoothing and peak load shaving }\end{array}$ & $\begin{array}{l}\text { Non-linear sequential quadratic } \\
\text { programming/ Coding }\end{array}$ \\
\hline$[54]$ & 2013 & $\mathrm{TP}+\mathrm{DE}$ & $\begin{array}{c}\text { Application of load leveling using ES system with the aim of } \\
\text { DN loss reduction }\end{array}$ & $\begin{array}{l}\text { Distribution power flow/ } \\
\text { Matlab \& coding }\end{array}$ \\
\hline$[55]$ & 2009 & $\mathrm{TP}+\mathrm{DM}$ & $\begin{array}{c}\text { Minimization of power loss and voltage error using LPCs } \\
\text { which are designed based on technology of back-back } \\
\text { converters }\end{array}$ & Optimal power flow \\
\hline$[56]$ & 2017 & $\mathrm{TP}+\mathrm{DM}$ & $\begin{array}{l}\text { Volt/VAR management using SOP, OLTC and circuit } \\
\text { breakers to minimize operational cost and voltage deviation }\end{array}$ & $\begin{array}{l}\text { Mixed-integer second-order } \\
\text { cone programming/ Matlab \& } \\
\text { YALMIP toolbox }\end{array}$ \\
\hline [57] & 2015 & $\mathrm{TP}+\mathrm{TC}$ & $\begin{array}{c}\text { Transient zonal based Volt/VAR management of DN using } \\
\text { DSTATCOMs, shunt capacitors, OLTCs, and voltage-source } \\
\text { converter interfaced DGs }\end{array}$ & MATLAB/Simulink \\
\hline$[58]$ & 2017 & $\mathrm{TP}+\mathrm{TC}$ & $\begin{array}{c}\text { Transient Volt/VAR management of DN considering } \\
\text { nonlinearities of OLTC }\end{array}$ & $\begin{array}{l}\text { YALMIP toolbox of Matlab } \\
\text { with BNB solver }\end{array}$ \\
\hline [59] & 2012 & $\mathrm{TP}+\mathrm{TC}$ & A comprehensive review on different methods of voltage & N/A \\
\hline
\end{tabular}




\begin{tabular}{|c|c|c|c|c|}
\hline & & & control for ADSs & \\
\hline$[60]$ & 2016 & $\mathrm{TP}+\mathrm{TC}$ & $\begin{array}{c}\text { Transient frequency stability improvement of grid utilizing } \\
\text { decentralized active DR }\end{array}$ & N/A \\
\hline [61] & 2016 & $\mathrm{TP}+\mathrm{TC}$ & $\begin{array}{c}\text { Presenting a proper regulatory framework to allow DR } \\
\text { network services for DSO in Europe }\end{array}$ & N/A \\
\hline$[62]$ & 2016 & $\mathrm{TP}+\mathrm{TC}$ & $\begin{array}{l}\text { Transient voltage and frequency response improvement of } \\
\text { ADS under grid-connected/islanding operating conditions }\end{array}$ & PSCAD \& Simulink \\
\hline$[63]$ & 2016 & $\mathrm{MC}+\mathrm{OI}$ & $\begin{array}{l}\text { Reliability evaluation using Monte-Carlo simulation to } \\
\text { demonstrate impacts of DGs, ES, and DN reliability }\end{array}$ & $\begin{array}{l}\text { Monte-Carlo simulation/ } \\
\text { coding }\end{array}$ \\
\hline [64] & 2015 & $\mathrm{MC}+\mathrm{OI}$ & $\begin{array}{c}\text { Power loss and Volt/VAR evaluation of DN based on a pilot } \\
\text { experience of DG integration into ADS }\end{array}$ & N/A \\
\hline$[65]$ & 2016 & $\mathrm{MC}+\mathrm{OI}$ & $\begin{array}{l}\text { Controllability evaluation of current/voltage in the } \\
\text { buses/lines of ADS including single/multi MGs }\end{array}$ & $\begin{array}{l}\text { Tabu search optimization } \\
\text { algorithm/ Matlab \& coding }\end{array}$ \\
\hline$[66]$ & 2015 & $\mathrm{MC}+\mathrm{OI}$ & $\begin{array}{l}\text { Assessment of impacts of ADS presence in risk evaluation of } \\
\text { transmission networks }\end{array}$ & $\begin{array}{l}\text { Optimal power flow and a } \\
\text { hierarchical procedure/ Coding }\end{array}$ \\
\hline$[67]$ & 2014 & $\mathrm{MC}+\mathrm{OI}$ & $\begin{array}{c}\text { Monte-Carlo based reliability assessment of ADS with } \\
\text { low/high DG penetration levels }\end{array}$ & $\begin{array}{l}\text { Monte-Carlo simulation/ } \\
\text { Matlab \& coding }\end{array}$ \\
\hline$[68]$ & 2015 & $\mathrm{MC}+\mathrm{OI}$ & $\begin{array}{c}\text { Monte-Carlo based capacity credit evaluation of different } \\
\text { mixes of DGs in ADSs including DR }\end{array}$ & $\begin{array}{l}\text { Monte-Carlo simulation/ } \\
\text { Matlab \& coding }\end{array}$ \\
\hline [69] & 2016 & $\mathrm{MC}+\mathrm{OI}$ & $\begin{array}{l}\text { Developing an approach to assess capabilities of ADS for } \\
\text { grid stability support and bulk ancillary service in energy } \\
\text { market }\end{array}$ & $\begin{array}{l}\text { Optimal power flow in an } \\
\text { iterative procedure/ Coding }\end{array}$ \\
\hline [70] & 2016 & $\mathrm{MC}+\mathrm{OI}$ & $\begin{array}{l}\text { Evaluating the future reliability of grid from the } \\
\text { current state of system using big data methodology }\end{array}$ & $\begin{array}{l}\text { Artificial neural network/ } \\
\text { Matlab \& toolbox }\end{array}$ \\
\hline [71] & 2014 & $\mathrm{MC}+\mathrm{PF}$ & $\begin{array}{l}\text { Proposing an improvement in three-phase forward-backward } \\
\text { sweep power flow to handle P-V nodes utilizing loop analysis }\end{array}$ & $\begin{array}{l}\text { Power flow analysis/ } \mathrm{C}-\mathrm{C}++\& \\
\text { Coding }\end{array}$ \\
\hline [72] & 2016 & $\mathrm{MC}+\mathrm{PF}$ & $\begin{array}{l}\text { Overcoming non-convex characteristics of traditional power } \\
\text { flow through adding some linear constraints and adding a } \\
\text { multi-temporal technique to assess the benefits of ES } \\
\text { incorporation }\end{array}$ & $\begin{array}{l}\text { Power flow analysis - second } \\
\text { order cone programming/ } \\
\text { Matlab \& coding }\end{array}$ \\
\hline [73] & 2015 & $\mathrm{MC}+\mathrm{PF}$ & $\begin{array}{l}\text { Utilizing symmetrical components based three-phase power } \\
\text { flow to analysis impacts of DERs on DN }\end{array}$ & $\begin{array}{l}\text { Power flow analysis/ C++ \& } \\
\text { coding and Simulink }\end{array}$ \\
\hline$[74]$ & 2016 & $\mathrm{MC}+\mathrm{PF}$ & $\begin{array}{c}\text { Study of problems related to approximate solutions of } \\
\text { active/reactive power balance in power flow and provision of } \\
\text { a linear formulation to obtain the approximate power value of } \\
\text { P-Q buses }\end{array}$ & $\begin{array}{l}\text { Power flow analysis/ Matlab \& } \\
\text { coding }\end{array}$ \\
\hline$[75]$ & 2011 & $\mathrm{MC}+\mathrm{PF}$ & $\begin{array}{c}\text { Proposing a novel power flow which modifies bus voltages } \\
\text { based on grid data and reactive power injection of P-V nodes; } \\
\text { for both the radial/weakly meshed DNs as well as } \\
\text { transmission grids }\end{array}$ & $\begin{array}{l}\text { Power flow analysis/ Matlab \& } \\
\text { coding }\end{array}$ \\
\hline [76] & 2016 & $\mathrm{MC}+\mathrm{PF}$ & $\begin{array}{c}\text { An optimal power flow to assist the DSO in case of economic } \\
\text { scheduling of DER units in unbalanced DN considering } \\
\text { economics of market }\end{array}$ & $\begin{array}{l}\text { Imperialist competitive } \\
\text { algorithm/ Matlab \& coding }\end{array}$ \\
\hline [77] & 2017 & $\mathrm{MC}+\mathrm{PF}$ & $\begin{array}{l}\text { Formulation of two types of cutting planes based optimal } \\
\text { power flow in ADS using second order cone programming }\end{array}$ & $\begin{array}{c}\text { Benders decomposition } \\
\text { technique/ GAMS \& CONOPT }\end{array}$ \\
\hline [78] & 2015 & $\mathrm{MC}+\mathrm{NM}$ & $\begin{array}{c}\text { An extensive research on analysis, modeling and control of } \\
\text { DERs with voltage/current source converters in isolated/grid- } \\
\text { connected DNs }\end{array}$ & Matlab/Simulink \\
\hline [79] & 2016 & $\mathrm{MC}+\mathrm{NM}$ & $\begin{array}{l}\text { A comprehensive survey on modeling and state estimation of } \\
\text { ADSs }\end{array}$ & N/A \\
\hline [80] & 2016 & $\mathrm{MC}+\mathrm{NM}$ & $\begin{array}{c}\text { Modeling of industrial CAES including size of compressor } \\
\text { and storage }\end{array}$ & $\begin{array}{c}\text { Mixed-integer programing/ } \\
\text { Gurobi \& optimization toolbox }\end{array}$ \\
\hline [81] & 2016 & $\mathrm{MC}+\mathrm{NM}$ & $\begin{array}{c}\text { Modeling of centralized thermal overload management with } \\
\text { significant DGs integration in ADSs considering minimum } \\
\text { curtailment of dispatchable DERs }\end{array}$ & $\begin{array}{c}\text { Mixed-integer and } \\
\text { quadratically constrained } \\
\text { programming with branch and } \\
\text { bound/ GAMS \& CPLEX, and } \\
\text { CONOPT }\end{array}$ \\
\hline [82] & 2017 & $\mathrm{MC}+\mathrm{NM}$ & $\begin{array}{c}\text { Modeling of energy efficiency effects on electricity } \\
\text { customers and demonstration for decrease of energy } \\
\text { consumption in residential sector considering home appliance } \\
\text { replacements. }\end{array}$ & $\begin{array}{l}\text { An iterative procedure/ } \\
\text { MATLAB \& coding }\end{array}$ \\
\hline
\end{tabular}




\begin{tabular}{|c|c|c|c|c|}
\hline$[83]$ & 2015 & MC+CR & $\begin{array}{c}\text { Investigating the agent-based management of ADSs and a } \\
\text { short survey on control and communication requirements of } \\
\text { forming a set of connected virtual MGs }\end{array}$ & $\begin{array}{c}\text { Tabu search optimization } \\
\text { algorithm and graph-theory } \\
\text { based techniques/ Matlab \& } \\
\text { coding }\end{array}$ \\
\hline$[84]$ & 2011 & MC+CR & $\begin{array}{c}\text { Decentralized voltage and frequency control of ADS } \\
\text { islanding mode of network }\end{array}$ & $\begin{array}{c}\text { A protocol based } \\
\text { communication software }\end{array}$ \\
\hline$[85]$ & 2013 & MC+CR & $\begin{array}{c}\text { Proposing a multi-level hierarchical control strategy for } \\
\text { secondary control of ADSs }\end{array}$ & N/A \\
\hline$[86]$ & 2016 & MC+CR & $\begin{array}{c}\text { Decentralized control of ADSs for load restoration based on } \\
\text { customers' priority and expert system rules }\end{array}$ & $\begin{array}{c}\text { Power flow analysis/ Matlab \& } \\
\text { coding }\end{array}$ \\
\hline$[87]$ & 2016 & MC+CR & $\begin{array}{r}\text { Presenting results of a practical implementation of agent } \\
\text { based control on a DN }\end{array}$ & N/A \\
\hline
\end{tabular}

MAIN CATOGIRIES $\rightarrow$ EM: Economic management, TP: Technical management and power quality improvement, MC: Modeling and control development of ADSs, N/A: not available/applicable.

SUB-CATOGIRIES $\rightarrow$ DS: Day-ahead scheduling of DERs and ES systems, DI: Participation of DISCOs in wholesale market, OC: Optimal control of PEV loads, MF: MG formation for decentralized management of ADS, SR: Static reactive power optimization of grid, SM: Static multiobjective operation of grid, DR: Dynamic reconfiguration management of grid, DP: Dynamic power loss and voltage profile management, DE: Dynamic ES system management, DM: Dynamic management of active/reactive power controllers, TC: Transient control and operation of grid, OI: Assessment of operation indices of grid, PF: Power flow as a tool for grid performance evaluation, NM: Novel modelling approaches of grid, CR: Communication and control requirements of ADSs

\section{Conclusion}

With the emergence of ADSs, as the result of the incorporation of active elements in DNs, significant changes happened in both of the planning and operation aspects of DNs. In this paper, an in-depth survey of recent literature in regards to ADSs is presented. To highlight the most important features, the operation of the DNs from economic and technical aspects was firstly explored. Incorporation of different participants is characterized regarding economic factors; while different time horizons have been investigated in the technical management of ADS. Finally, some features necessary for an active operation of DNs regarding modeling and communication requirements have also been presented. The obtained categories provided in this study can assist grid operators to achieve the most efficient approaches of ADS operation. In all of these areas of applications, there is always a necessity for collaborating with DN companies to explore existing facilities and management approaches and subsequently to put forward some novel practical solutions.

\section{REFERENCES}

[1] Y. You, D. Liu, W. Yu, F. Chen, and F. Pan, "Technology and its trends of active distribution network," Dianli Xitong Zidonghua(Automation of Electric Power Systems), vol. 36, no. 18, pp. 10-16, 2012.

[2] J. McDonald, "Adaptive intelligent power systems: Active distribution networks," Energy Policy, vol. 36, no. 12, pp. 4346-4351, 2008.

[3] D. Trebolle, P. Hallberg, G. Lorenz, P. Mandatova, and J. T. Guijarro, "Active distribution system management," in Electricity Distribution (CIRED 2013), 22nd International Conference and Exhibition on, 2013, pp. 1-4: IET.

[4] P. Hallberg, "Active distribution system management a key tool for the smooth integration of distributed generation," Eurelectric TF Active System Management, vol. 2, no. 13, 2013.

[5] S. Ruester, S. Schwenen, C. Batlle, and I. Pérez-Arriaga, "From distribution networks to smart distribution 

M. Fan, Z. Zhang, A. Su, and J. Su, "Enabling technologies for active distribution systems," Proceedings of the CSEE, vol. 33, no. 22, pp. 12-18, 2013.

[7] V. A. Evangelopoulos, P. S. Georgilakis, and N. D. Hatziargyriou, "Optimal operation of smart distribution networks: A review of models, methods and future research," Electric Power Systems Research, vol. 140, pp. 95-106, 2016.

[8] X. Zhao, Q. Chen, Q. Xia, C. Kang, and H. Wang, "Multi-period coordinated active-reactive scheduling of active distribution system," in Power and Energy Society General Meeting (PES), 2013 IEEE, 2013, pp. 1-5: IEEE.

[9] A. A. Ibrahim, B. Kazemtabrizi, and C. Dent, "Operational planning and optimisation in active distribution networks using modern intelligent power flow controllers," in PES Innovative Smart Grid Technologies Conference Europe (ISGT-Europe), 2016 IEEE, 2016, pp. 1-6: IEEE.

[10] H. Gao, J. Liu, and L. Wang, "Robust Coordinated Optimization of Active and Reactive Power in Active Distribution Systems," IEEE Transactions on Smart Grid, 2017.

[11] J. Duan, T. Mu, F. Yan, L. Chen, K. Wang, and Y. Lei, "Optimization schedule of active distribution system based on improved harmony search algorithm," in Electric Utility Deregulation and Restructuring and Power Technologies (DRPT), 2015 5th International Conference on, 2015, pp. 2678-2683: IEEE.

[12] A. Borghetti et al., "Short-term scheduling and control of active distribution systems with high penetration of renewable resources," IEEE Systems Journal, vol. 4, no. 3, pp. 313-322, 2010.

[13] A. Saint-Pierre and P. Mancarella, "Active distribution system management: a dual-horizon scheduling framework for DSO/TSO interface under uncertainty," IEEE Transactions on Smart Grid, 2016.

[14] S. Sekizaki, I. Nishizaki, and T. Hayashida, "Electricity retail market model with flexible price settings and elastic price-based demand responses by consumers in distribution network," International Journal of Electrical Power \& Energy Systems, vol. 81, pp. 371-386, 2016.

[15] H. H. Abdeltawab and Y. A.-R. I. Mohamed, "Mobile Energy Storage Scheduling and Operation in Active Distribution Systems," IEEE Transactions on Industrial Electronics, 2017.

[16] A. Zakariazadeh, S. Jadid, and P. Siano, "Multi-objective scheduling of electric vehicles in smart distribution system," Energy Conversion and Management, vol. 79, pp. 43-53, 2014.

[17] Y. Xiang, J. Liu, and Y. Liu, "Optimal active distribution system management considering aggregated plugin electric vehicles," Electric Power Systems Research, vol. 131, pp. 105-115, 2016.

[18] M. H. Imani, K. Yousefpour, M. J. Ghadi, and M. T. Andani, "Simultaneous presence of wind farm and V2G in security constrained unit commitment problem considering uncertainty of wind generation," in Texas Power and Energy Conference (TPEC), 2018 IEEE, 2018, pp. 1-6: IEEE.

[19] G. Bharati and S. Paudyal, "Coordinated control of distribution grid and electric vehicle loads," Electric Power Systems Research, vol. 140, pp. 761-768, 2016.

[20] S. Faddel, A. A. Mohamed, and O. A. Mohammed, "Fuzzy logic-based autonomous controller for electric vehicles charging under different conditions in residential distribution systems," Electric Power Systems Research, vol. 148, pp. 48-58, 2017.

[21] N. O’Connell, Q. Wu, J. Østergaard, A. H. Nielsen, S. T. Cha, and Y. Ding, "Day-ahead tariffs for the alleviation of distribution grid congestion from electric vehicles," Electric Power Systems Research, vol. 92, pp. 106-114, 2012.

[22] I. G. Unda, P. Papadopoulos, S. Skarvelis-Kazakos, L. M. Cipcigan, N. Jenkins, and E. Zabala, "Management of electric vehicle battery charging in distribution networks with multi-agent systems," Electric Power Systems Research, vol. 110, pp. 172-179, 2014.

[23] V. T. Bina and D. Ahmadi, "Stochastic modeling for scheduling the charging demand of EV in distribution systems using copulas," International Journal of Electrical Power \& Energy Systems, vol. 71, pp. 15-25, 2015.

[24] S. Chowdhury and P. Crossley, Microgrids and active distribution networks. The Institution of Engineering and Technology, 2009.

[25] M. A. Zehir et al., "Impacts of microgrids with renewables on secondary distribution networks," Applied Energy, 2017.

[26] S. A. Arefifar, Y. A.-R. I. Mohamed, and T. H. El-Fouly, "Supply-adequacy-based optimal construction of microgrids in smart distribution systems," IEEE transactions on smart grid, vol. 3, no. 3, pp. 1491-1502, 2012 .

[27] S. A. Arefifar and Y. A.-R. I. Mohamed, "DG mix, reactive sources and energy storage units for optimizing microgrid reliability and supply security," IEEE Transactions on Smart Grid, vol. 5, no. 4, pp. 1835-1844, 2014.

[28] A. K. Marvasti, Y. Fu, S. DorMohammadi, and M. Rais-Rohani, "Optimal operation of active distribution grids: A system of systems framework," IEEE Transactions on Smart Grid, vol. 5, no. 3, pp. 1228-1237, 2014. 
[29] A. Azizivahed, S. Ghavidel, M. J. Ghadi, L. Li, and J. Zhang, "New energy management approach in distribution systems considering energy storages," in Electrical Machines and Systems (ICEMS), 2017 20th International Conference on, 2017, pp. 1-6: IEEE.

[30] A. Kargarian and Y. Fu, "System of systems based security-constrained unit commitment incorporating active distribution grids," IEEE Trans. Power Syst, vol. 29, no. 5, pp. 2489-2498, 2014.

[31] J. Zhang, H. Cheng, and C. Wang, "Technical and economic impacts of active management on distribution network," International Journal of Electrical Power \& Energy Systems, vol. 31, no. 2-3, pp. 130-138, 2009.

[32] S. Abapour, E. Babaei, and B. Y. Khanghah, "Application of active management on distribution network with considering technical issues," in Smart Grids (ICSG), 2012 2nd Iranian Conference on, 2012, pp. 1-6: IEEE.

[33] X. Dai, "Study on Reactive Power Optimization of Active Distribution Network Based on Bifurcation Theory," 2015.

[34] Y. Feng, Y. Li, Y. Cao, and Y. Zhou, "Automatic voltage control based on adaptive zone-division for active distribution system," in Power and Energy Engineering Conference (APPEEC), 2016 IEEE PES Asia-Pacific, 2016, pp. 278-282: IEEE.

[35] T. Zhao, J. Zhang, and P. Wang, "Flexible active distribution system management considering interaction with transmission networks using information-gap decision theory," CSEE Journal of Power and Energy Systems, vol. 2, no. 4, pp. 76-86, 2016.

[36] L. Mokgonyana, J. Zhang, L. Zhang, and X. Xia, "Coordinated two-stage volt/var management in distribution networks," Electric Power Systems Research, vol. 141, pp. 157-164, 2016.

[37] M. McGranaghan and F. Goodman, "Technical and system requirements for advanced distribution automation," in 18th International Conference and Exhibition on Electricity Distribution, 2005, vol. 5, p. 93 : IET.

[38] F. Capitanescu, I. Bilibin, and E. R. Ramos, "A comprehensive centralized approach for voltage constraints management in active distribution grid," IEEE Transactions on Power Systems, vol. 29, no. 2, pp. 933-942, 2014.

[39] W. Zheng, W. Wu, B. Zhang, H. Sun, and Y. Liu, "A fully distributed reactive power optimization and control method for active distribution networks," IEEE Transactions on Smart Grid, vol. 7, no. 2, pp. 1021-1033, 2016.

[40] Y. Wang, W. Wu, B. Zhang, Z. Li, and W. Zheng, "Robust voltage control model for active distribution network considering PVs and loads uncertainties," in Power \& Energy Society General Meeting, 2015 IEEE, 2015, pp. 1-5: IEEE.

[41] Q. Zhu, J. Zhang, P. W. Sauer, A. Domínguez-García, and T. Başar, "A game-theoretic framework for control of distributed renewable-based energy resources in smart grids," in American Control Conference (ACC), 2012, 2012, pp. 3623-3628: IEEE.

[42] C.-y. Ma, Q. Duan, C.-k. Shi, Z.-p. Lv, and Y.-1. Li, "Research on power quality improvement of active distribution grid based on power electronic transformer," in Electricity Distribution (CICED), 2014 China International Conference on, 2014, pp. 939-943: IEEE.

[43] T. Lv and Q. Ai, "Interactive energy management of networked microgrids-based active distribution system considering large-scale integration of renewable energy resources," Applied Energy, vol. 163, pp. 408-422, 2016.

[44] F. Capitanescu, L. F. Ochoa, H. Margossian, and N. D. Hatziargyriou, "Assessing the potential of network reconfiguration to improve distributed generation hosting capacity in active distribution systems," IEEE Transactions on Power Systems, vol. 30, no. 1, pp. 346-356, 2015.

[45] I. Bilibin and F. Capitanescu, "Contributions to thermal constraints management in radial active distribution systems," Electric Power Systems Research, vol. 111, pp. 169-176, 2014.

[46] I. Coroamă, G. Chicco, M. Gavrilaş, and A. Russo, "Distribution system optimisation with intra-day network reconfiguration and demand reduction procurement," Electric Power Systems Research, vol. 98, pp. 29-38, 2013.

[47] F. Zhao, J. Si, and J. Wang, "Research on optimal schedule strategy for active distribution network using particle swarm optimization combined with bacterial foraging algorithm," International Journal of Electrical Power \& Energy Systems, vol. 78, pp. 637-646, 2016.

[48] M. Degefa, M. Lehtonen, R. Millar, A. Alahäivälä, and E. Saarijärvi, "Optimal voltage control strategies for day-ahead active distribution network operation," Electric Power Systems Research, vol. 127, pp. 41-52, 2015.

[49] M. A. Ghasemi and M. Parniani, "Prevention of distribution network overvoltage by adaptive droop-based active and reactive power control of PV systems," Electric Power Systems Research, vol. 133, pp. 313-327, 2016.

[50] M. Bahramipanah, R. Cherkaoui, and M. Paolone, "Decentralized voltage control of clustered active distribution network by means of energy storage systems," Electric Power Systems Research, vol. 136, pp. 370-382, 2016. 
[51] M. Farrokhifar, "Optimal operation of energy storage devices with RESs to improve efficiency of distribution grids; technical and economical assessment," International Journal of Electrical Power \& Energy Systems, vol. 74, pp. 153-161, 2016.

[52] M. Koller, T. Borsche, A. Ulbig, and G. Andersson, "Review of grid applications with the Zurich 1MW battery energy storage system," Electric Power Systems Research, vol. 120, pp. 128-135, 2015.

[53] E. Reihani, S. Sepasi, L. R. Roose, and M. Matsuura, "Energy management at the distribution grid using a Battery Energy Storage System (BESS)," International Journal of Electrical Power \& Energy Systems, vol. 77, pp. 337-344, 2016.

[54] H. Saboori and H. Abdi, "Application of a grid scale energy storage system to reduce distribution network losses," in Electrical Power Distribution Networks (EPDC), 2013 18th Conference on, 2013, pp. 1-5: IEEE.

[55] N. Okada, "A method to determine the distributed control setting of looping devices for active distribution systems," in PowerTech, 2009 IEEE Bucharest, 2009, pp. 1-6: IEEE.

[56] P. Li et al., "A Coordinated Control Method of Voltage and Reactive Power for Active Distribution Networks Based on Soft Open Point," IEEE Transactions on Sustainable Energy, 2017.

[57] J. Barr and R. Majumder, "Integration of distributed generation in the volt/var management system for active distribution networks," IEEE Transactions on Smart Grid, vol. 6, no. 2, pp. 576-586, 2015.

[58] J. Morin, F. Colas, J.-Y. Dieulot, S. Grenard, and X. Guillaud, "Embedding OLTC nonlinearities in predictive Volt Var Control for active distribution networks," Electric Power Systems Research, vol. 143, pp. 225-234, 2017.

[59] T. T. Hashim, A. Mohamed, and H. Shareef, "A review on voltage control methods for active distribution networks," Prz. Elektrotech, vol. 88, pp. 304-312, 2012.

[60] G. Benysek, J. Bojarski, M. Jarnut, and R. Smolenski, "Decentralized Active Demand Response (DADR) system for improvement of frequency stability in distribution network," Electric Power Systems Research, vol. 134, pp. 80-87, 2016.

[61] M. Vallés, J. Reneses, R. Cossent, and P. Frías, "Regulatory and market barriers to the realization of demand response in electricity distribution networks: a European perspective," Electric Power Systems Research, vol. 140, pp. 689-698, 2016.

[62] R. Jamalzadeh, F. Zhang, and M. Hong, "An economic dispatch algorithm incorporating voltage management for active distribution systems using generalized benders decomposition," in Power and Energy Society General Meeting (PESGM), 2016, 2016, pp. 1-5: IEEE.

[63] H. Li et al., "Reliability evaluation of active distribution systems considering energy storage and real-time electricity pricing," in Probabilistic Methods Applied to Power Systems (PMAPS), 2016 International Conference on, 2016, pp. 1-5: IEEE.

[64] A. González, J. A. Saavedra, J. Tello-Guijarro, D. Trebolle, and M. Casas, "PRICE-GDI: A pilot experience for the integration of Distributed Generation in active distribution systems," in Smart Electric Distribution Systems and Technologies (EDST), 2015 International Symposium on, 2015, pp. 183-188: IEEE.

[65] S. A. Arefifar, M. Ordonez, and Y. Mohamed, "Voltage and current controllability in multi-microgrid smart distribution systems," IEEE Transactions on Smart Grid, 2016.

[66] H. Jia, W. Qi, Z. Liu, B. Wang, Y. Zeng, and T. Xu, "Hierarchical risk assessment of transmission system considering the influence of active distribution network," IEEE Transactions on Power Systems, vol. 30, no. 2, pp. 1084-1093, 2015.

[67] S. Ge, L. Xu, H. Liu, and M. Zhao, "Reliability assessment of active distribution system using Monte Carlo simulation method," Journal of Applied Mathematics, vol. 2014, 2014.

[68] X. Zheng, B. Zeng, G. Wu, J. Zhang, M. Zeng, and J. Shi, "Capacity credit assessment of renewable distributed generation in active distribution systems considering demand response impact," in Electric Utility Deregulation and Restructuring and Power Technologies (DRPT), 2015 5th International Conference on, 2015, pp. 108-113: IEEE.

[69] G. Petretto et al., "Representative distribution network models for assessing the role of active distribution systems in bulk ancillary services markets," in Power Systems Computation Conference (PSCC), 2016, 2016, pp. 1-7: IEEE.

[70] L. Hu, K.-Y. Liu, Y. Diao, X. Meng, and W. Sheng, "Operational Reliability Evaluation Method Based on Big Data Technology," in Cyber-Enabled Distributed Computing and Knowledge Discovery (CyberC), 2016 International Conference on, 2016, pp. 341-344: IEEE.

[71] Y. Ju, W. Wu, B. Zhang, and H. Sun, "An extension of FBS three-phase power flow for handling PV nodes in active distribution networks," IEEE Transactions on Smart Grid, vol. 5, no. 4, pp. 1547-1555, 2014.

[72] E. Grover-Silva, R. Girard, and G. Kariniotakis, "Multi-temporal optimal power flow for assessing the renewable generation hosting capacity of an active distribution system," in Transmission and Distribution Conference and Exposition (T\&D), 2016 IEEE/PES, 2016, pp. 1-5: IEEE.

[73] S. Syafii and K. Nor, "Unbalanced Active Distribution Analysis with Renewable Distributed Energy Resources," TELKOMNIKA (Telecommunication Computing Electronics and Control), vol. 13, no. 1, pp. 21- 
31, 2015.

[74] S. Bolognani and S. Zampieri, "On the existence and linear approximation of the power flow solution in power distribution networks," IEEE Transactions on Power Systems, vol. 31, no. 1, pp. 163-172, 2016.

[75] J. Olamaei, M. A. Ghasemabadi, and M. H. Kapourchali, "An efficient method for load flow analysis of distribution networks including PV nodes," in Electric Power and Energy Conversion Systems (EPECS), 2011 2nd International Conference on, 2011, pp. 1-6: IEEE.

[76] M. J. Ghadi, A. Baghramian, and M. H. Imani, "An ICA based approach for solving profit based unit commitment problem market," Applied Soft Computing, vol. 38, pp. 487-500, 2016.

[77] H. Gao, J. Liu, L. Wang, and Y. Liu, "Cutting planes based relaxed optimal power flow in active distribution systems," Electric Power Systems Research, vol. 143, pp. 272-280, 2017.

[78] A. A. Radwan, "Modeling, Analysis and Advanced Control of Voltage-and Current-source Converters in Renewable Energy-based Active Distribution Systems," University of Alberta, 2015.

[79] J. Chen, Y. Dong, and H. Zhang, "Distribution system state estimation: A survey of some relevant work," in Control Conference (CCC), 2016 35th Chinese, 2016, pp. 9985-9989: IEEE.

[80] M. Diekerhof, S. Hecker, and A. Monti, "Modeling and optimization of industrial compressed-air energy systems for Demand Response," in Energy Conference (ENERGYCON), 2016 IEEE International, 2016, pp. 1-6: IEEE.

[81] F. Capitanescu and I. Bilibin, "A tractable two-step MILP-QCP approach to on-line thermal constraint management in large radial active distribution systems," Electric Power Systems Research, vol. 140, pp. 580$587,2016$.

[82] M. Aghamohamadi and N. Amjady, "Modeling and Optimization for Costly Efficiency Improvements on Residential Appliances Considering Consumer's Income Level," IET Generation, Transmission \& Distribution, 2017.

[83] S. A. Arefifar, Y. A.-R. I. Mohamed, and T. El-Fouly, "Optimized multiple microgrid-based clustering of active distribution systems considering communication and control requirements," IEEE Transactions on Industrial Electronics, vol. 62, no. 2, pp. 711-723, 2015.

[84] S. T. Cha, Q. Wu, J. Østergaard, and A. Saleem, "Multi-agent based controller for islanding operation of active distribution networks with distributed generation (DG)," in Electric Utility Deregulation and Restructuring and Power Technologies (DRPT), 2011 4th International Conference on, 2011, pp. 803-810: IEEE.

[85] P. Wirasanti, E. Ortjohann, M. Hoppe, H. Saffour, S. Leksawat, and D. Morton, "Automated active distribution network with multi-level cluster control approach," in Industrial Electronics Society, IECON 2013-39th Annual Conference of the IEEE, 2013, pp. 1980-1985: IEEE.

[86] A. A. Hafez, W. A. Omran, and Y. G. Higazi, "A Decentralized Technique for Autonomous Service Restoration in Active Radial Distribution Networks," IEEE Transactions on Smart Grid, 2016.

[87] I. Kouveliotis-Lysikatos, D. Koukoula, A. Dimeas, N. Hatziargyriou, and S. Makrynikas, "Overview of decentralized distribution system operation techniques," 2016. 